\title{
Addressing Research and Development Gaps for Plasma-Material Interactions with Linear Plasma Devices
}

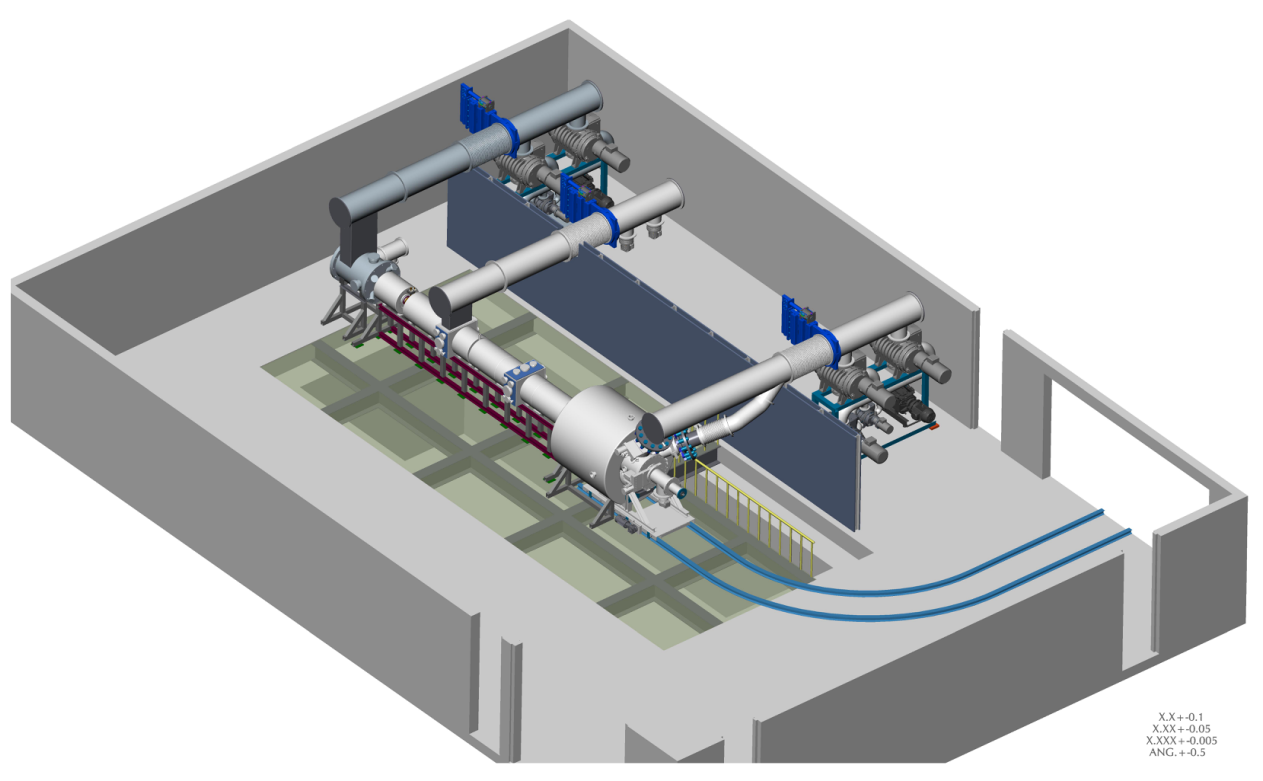

Approved for public release.

Distribution is unlimited.

J. Rapp

March 12, 2018 


\section{DOCUMENT AVAILABILITY}

Reports produced after January 1, 1996, are generally available free via US Department of Energy (DOE) SciTech Connect.

Website www.osti.gov

Reports produced before January 1, 1996, may be purchased by members of the public from the following source:

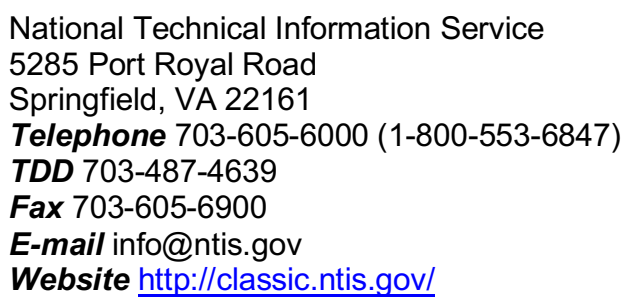

Reports are available to DOE employees, DOE contractors, Energy Technology Data Exchange representatives, and International Nuclear Information System representatives from the following source:

Office of Scientific and Technical Information

PO Box 62

Oak Ridge, TN 37831

Telephone 865-576-8401

Fax 865-576-5728

E-mail reports@osti.gov

Website http://www.osti.gov/contact.html

This report was prepared as an account of work sponsored by an agency of the United States Government. Neither the United States Government nor any agency thereof, nor any of their employees, makes any warranty, express or implied, or assumes any legal liability or responsibility for the accuracy, completeness, or usefulness of any information, apparatus, product, or process disclosed, or represents that its use would not infringe privately owned rights. Reference herein to any specific commercial product, process, or service by trade name, trademark, manufacturer, or otherwise, does not necessarily constitute or imply its endorsement, recommendation, or favoring by the United States Government or any agency thereof. The views and opinions of authors expressed herein do not necessarily state or reflect those of the United States Government or any agency thereof. 


\title{
ADDRESSING RESEARCH AND DEVELOPMENT GAPS FOR PLASMA-MATERIAL INTERACTIONS WITH LINEAR PLASMA DEVICES
}

\author{
J. Rapp
}

Date Published: March 12, 2018

Prepared by

OAK RIDGE NATIONAL LABORATORY

Oak Ridge, TN 37831-6283

managed by

UT-BATTELLE, LLC

for the

US DEPARTMENT OF ENERGY

under contract DE-AC05-00OR22725 



\section{CONTENTS}

LIST OF FIGURES

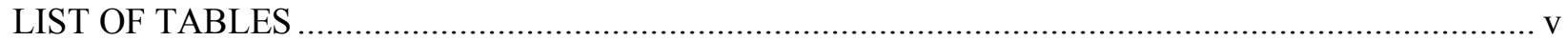

ACRONYMS

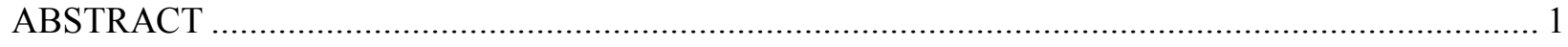

1. SCIENTIFIC NEEDS IN THE AREA OF PLASMA-MATERIAL INTERACTIONS .................... 1

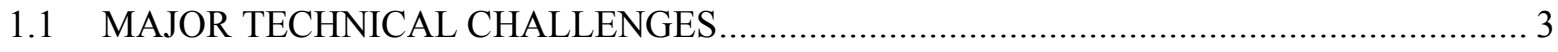

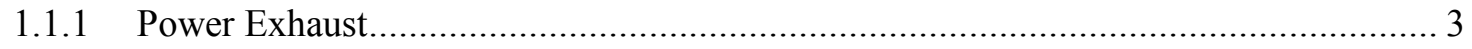

1.1.2 Plasma-Facing Component Lifetime …........................................................ 5

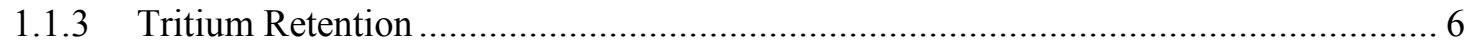

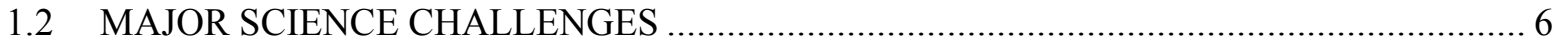

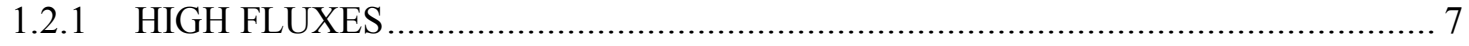

1.2.2 HIGH FLUENCE AND THE RELATED INCREASE IN COMPLEXITY OF THE STRONGLY EVOLVING SURFACES …................................................ 7

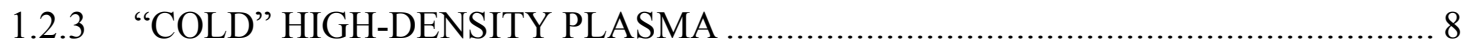

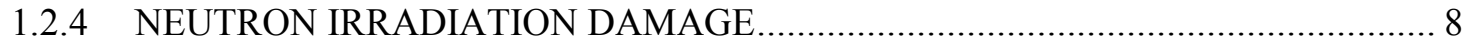

2. DISCUSSION OF CURRENT AND NEAR FUTURE FACILITIES AND EXPERIMENTAL

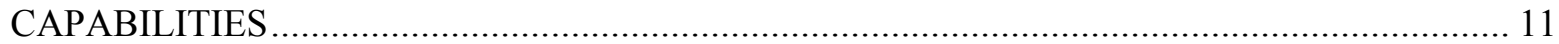

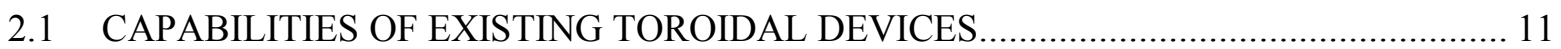

2.2 LIMITATIONS OF EXISTING TOROIDAL DEVICES ......................................... 12

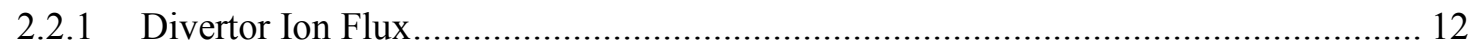

2.2.2 Divertor Ion Fluence........................................................................................ 12

2.2.3 Electron Density and Electron Temperature in Front of PFCs (Divertor or

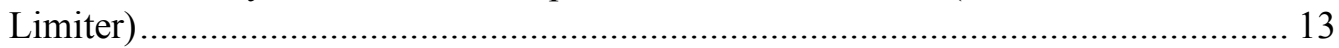

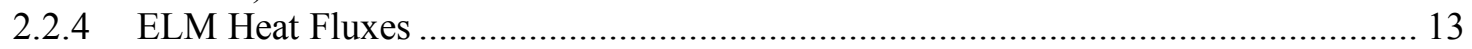

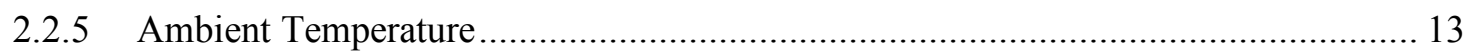

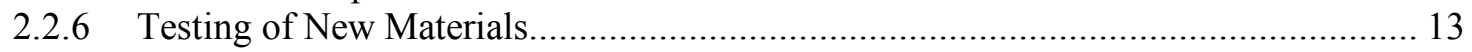

2.2.7 Test of Neutron-Irradiated Samples............................................................... 13

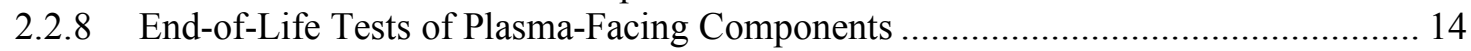

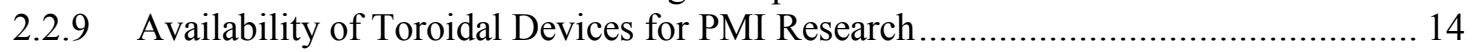

2.3 CAPABILITIES OF EXISTING LINEAR DEVICES .................................................. 14

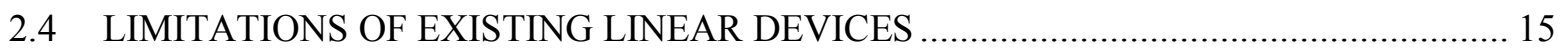

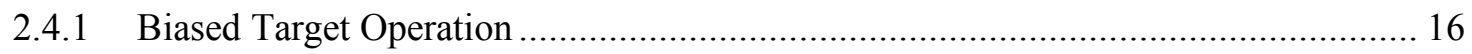

2.4.2 Limitation to Low Electron Temperature or Low Electron Density......................... 16

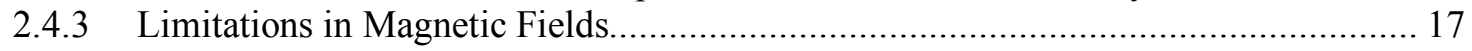

2.4.4 Ability to Study Conduction Limited Transport .............................................. 18

2.4.5 Ability to Study Neutron-Irradiated Materials ................................................... 18

3. NEED FOR UPGRADED OR NEW CAPABILITIES TO ADDRESS PMI SCIENCE GAPS ....... 21

4. THE PROPOSED MATERIAL PLASMA EXPOSURE EXPERIMENT (MPEX)...................... 25

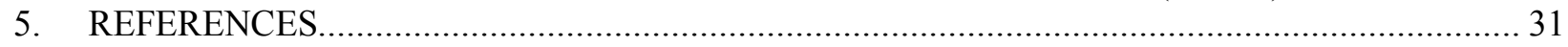

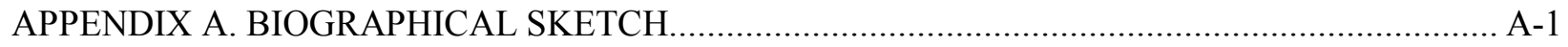





\section{LIST OF FIGURES}

Figure 1. Challenges for PMI in fusion reactor divertors as they increase from today's largest fusion device JET to ITER and then via FNSF to a fusion reactor......................................... 5

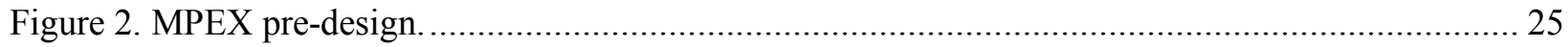

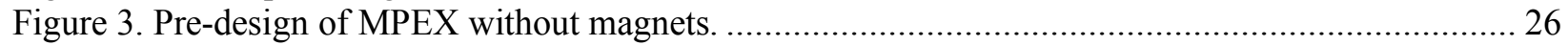

Figure 4. Contribution of MPEX to finding solutions for the development of plasma-facing components with addressing plasma material interactions at high fluence with materials, which have a priori exposure to high neutron fluence.

\section{LIST OF TABLES}

Table 1. Comparison of figures of merit for power exhaust and power dissipation among future reactor studies (PPCS A, ARIES-ACT1), ITER, and high-power discharges on JET and AUG......

Table 2. Irradiation damage and consequences for PMI.

Table 3. Ability of toroidal devices (national and international) to study fusion reactor-relevant

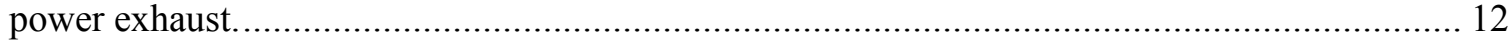

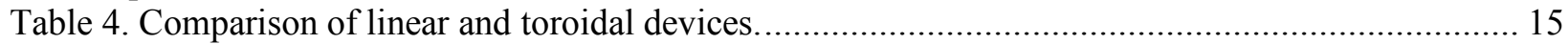

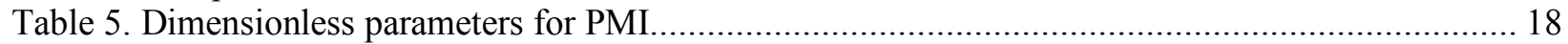

Table 6. PMI research areas and current contributions from tokamaks and linear devices to this research as well as research needs in the future. .................................................................. 21

Table 7. Plasma parameters achieved on Proto-MPEX (as of December 2017) compared with the target performance values. 



\section{ACRONYMS}

ARIES Advanced Reactor Innovation and Evaluation Study

ASDEX Axial Symmetric Divertor EXperiment

AUG

ASDEX Upgrade

CX

Charge eXchange

DBTT ductile-brittle transition temperature

DEMO DEMOnstration Power Station

DIII-D Doublet III-D fusion device

DIMES Divertor Material Evaluation Systems

EAST Experimental Advanced Superconducting Tokamak

EBW electron Bernstein waves

$\mathrm{ECH} \quad$ electron cyclotron heating

ELM edge localized modes

FESAC Fusion Energy Sciences Advisory Committee

FNSF Fusion Nuclear Science Facility

FOM Stichting voor Fundamenteel Onderzoek der Materie

ICH ion cyclotron heating

IEA International Energy Agency

INL Idaho National Laboratory

ISX Impurity Source eXperiment

ITER International Thermonuclear Experimental Reactor

ITER STAC International Thermonuclear Experimental Reactor Science and Technology Advisory Committee

JET Joint European Torus

KSTAR Korea Superconducting Tokamak Advanced Research

LH L to H-mode threshold

LHD Large Helical Device

LV long vertical target divertor

MAPES Material and Plasma Evaluation System

MAPP Materials Analysis and Particle Probe

MARFE multifaceted asymmetric radiation from the edge

MAST Mega Ampere Spherical Tokamak

MFP mean-free path

MPEX Material Plasma Exposure eXperiment 


$\begin{array}{ll}\text { NSTX } & \text { National Spherical Torus Experiment Upgrade } \\ \text { OFES } & \text { Office of Fusion Energy Sciences } \\ \text { ORMAK } & \text { Oak Ridge Tokamak } \\ \text { PFC } & \text { plasma-facing components } \\ \text { PHENIX } & \text { Pioneering High Energy Nuclear Interaction eXperiment } \\ \text { PISCES } & \text { Plasma surface interaction experimental facility } \\ \text { PMI } & \text { plasma-material interactions } \\ \text { PPCS } & \text { Power Plant Conceptual Study } \\ \text { QSPA } & \text { quasi-stationary plasma accelerators } \\ \text { R\&D } & \text { research and development } \\ \text { RF } & \text { radio frequency } \\ \text { SF } & \text { snowflake divertor } \\ \text { SOL } & \text { scrape-off-layer } \\ \text { SXD } & \text { Super-X-Divertor } \\ \text { TEXTOR } & \text { Toroidal EXperiment for Technical Oriented Research } \\ \text { TFTR } & \text { Tokamak Fusion Test Reactor } \\ \text { TPE } & \text { Tritium Plasma Experiment } \\ \text { TRL } & \text { technical readiness level }\end{array}$




\begin{abstract}
Plasma-material interactions in future fusion reactors have been identified as a knowledge gap to be dealt with before any next step device past ITER can be built. The challenges are manifold. They are related to power dissipation so that the heat fluxes to the plasma-facing components can be kept at technologically feasible levels; maximization of the lifetime of divertor plasma-facing components that allow for steadystate operation in a reactor to reach the neutron fluence required; the tritium inventory (storage) in the plasma-facing components, which can lead to potential safety concerns and reduction in the fuel efficiency; and it is related to the technology of the plasma-facing components itself, which should demonstrate structural integrity under the high temperatures and high neutron fluence. While the dissipation of power exhaust can and should be addressed in high power toroidal devices, the interaction of the plasma with the materials can be best addressed in dedicated linear devices due to their cost effectiveness and ability to address urgent research and development gaps more timely. However, new linear plasma devices are needed to investigate the PMI under fusion reactor conditions and test novel plasma-facing components. Existing linear devices are limited either in their flux, their reactor-relevant plasma transport regimes in front of the target, their fluence, or their ability to test material samples a priori exposed to high neutron fluence. The proposed Material Plasma Exposure eXperiment (MPEX) is meant to address those deficiencies and will be designed to fulfill the fusion reactor-relevant plasma parameters as well as the ability to expose a priori neutron activated materials to plasmas.
\end{abstract}

\title{
1. SCIENTIFIC NEEDS IN THE AREA OF PLASMA-MATERIAL INTERACTIONS
}

The scientific demonstration of magnetic fusion energy as an environmentally sustainable and economically competitive energy source will require mastering the science of plasma-material interactions (PMI) and developing plasma-facing components (PFC) that exhibit unprecedented erosion resistance and self-healing capability during prolonged exposure to high particle/heat fluxes and intense deuterium-tritium (D-T) fusion neutrons. The limited lifetime of PFCs will impact the availability of a fusion reactor and its economic viability. In addition, PMI impact the performance of the core fusion plasma, such as through the release of impurities, leading to dilution of the plasma fuel and radiative power losses. Even before the lifetime of a PFC is reached, stringently controlled in-vessel inventories of dust and tritium could stop reactor operation due to PMI in the nuclear environment. An improved understanding of the degradation mechanisms associated with PMI is needed to identify potential PFC materials and operational regimes.

PMI and the uncertain impact of the neutron irradiation have been identified in numerous expert panel reports by the fusion community. The 2007 Greenwald report [1] classifies PFCs and materials as the only Tier 1 issues requiring a ". . . major extrapolation from the current state of knowledge, need for qualitative improvements and substantial development for both the short and long term." The report goes on to list 19 gaps in understanding and performance related to the plasma-material interface for technology research facilities needed for DEMOnstration Power Station-oriented research and development and the DEMO itself.

The 2009 Department of Energy Research Needs for Magnetic Fusion Energy Sciences (ReNeW) report on fusion research needs [2] and the 2008 European Fusion Facilities Review Panel report [3] describe the types of new PMI research facilities that will be required to resolve issues related to the knowledge gaps identified by the fusion community. Specifically, ReNeW Thrust 10, titled "Decode and Advance the Science and Technology of Plasma-Surface Interactions," identifies the need for a new advanced PMI test stand, while a more recent (2012) Fusion Energy Sciences Advisory Committee (FESAC) report by Zinkle et al. [4] assesses the available PMI and other fusion technology research facilities and came to the following overarching finding: 
Most existing US fusion technology test stands are no longer unique or world-leading. However, numerous compelling opportunities for high-impact fusion research may be achievable by making. . .moderate investment[s] in new medium-scale facilities.

The FESAC report by Zinkle et al., titled Opportunities for Fusion Materials Science and Technology Research Now and During the ITER Era [4], identifies three key grand challenges for PMI (P1-P3):

1. "Understand and mitigate the deleterious effects in plasma-facing materials from both intense fusion neutron and plasma exposure that continuously damages the materials surrounding the plasma."

2. "Understand, predict and manage the material erosion and migration that will occur in the month-toyear-long plasma durations required in [the Fusion Nuclear Science Facility (FNSF)]/DEMO devices, due to plasma-material interactions and scrape-off layer plasma processes."

3. "Understand the coupled evolution of the plasma and PFCs under prototypical thermal, physical and chemical conditions expected in an FNSF/DEMO."

The 2013 FESAC report of a panel chaired by Robert Rosner [5] ranks ReNeW Thrust 10 among the five highest priority initiatives and endorses the need for new and upgraded PMI facilities to address the PMI gaps identified in ReNeW.

The Report on Strategic Planning: Priorities Assessment and Budget Scenarios [6] describes FESAC's 10 -year strategic plan and identifies high-priority initiatives for fusion technology development in the United States. The highest priorities (Tier 1) were assigned to initiatives related to the control of deleterious transient events and the taming of the plasma-material interface. After this report was issued, the Office of Fusion Energy Sciences (OFES) provided additional input and recommended that the highpriority initiative "Experimentally Validated Integrated Predictive Capabilities" be elevated from Tier 2 to Tier 1. OFES then sought further community input on scientific challenges and opportunities through a series of technical workshops in 2015 on priority research areas. This exercise was considered a success by the Office of Science and fed into the strategic planning process of OFES. The result was an OFES strategic plan submitted to Congress. This strategic plan was presented to FESAC and a vision for the US fusion program was developed [7]:

The vision described builds on the present U.S. activities in fusion plasma and material science relevant to the energy goal and extends plasma science at the frontier of discovery. The plan is founded on recommendations made by the National Academies, several recent studies by the Fusion Energy Sciences Advisory Committee (FESAC), and the Administration's views on the greatest opportunities for U.S. scientific leadership.

Among the five areas of major importance to the US fusion energy science enterprise over the next decade, that were mentioned in the strategic plan, is material science, which is strongly related to PMI. Material science, as it relates to plasma and fusion sciences, will provide the scientific foundations for greatly improved plasma confinement and heat exhaust.

Following this strategic planning exercise, several community workshops were hold. One of them, the Plasma Material Interactions Workshop [8] illuminated several areas of importance and identified five important priority research directions:

1. Identify the present limits on power and particle handling, as well as tritium control and inventory, for solid and liquid PFC, and extend performance to reactor-relevant conditions with new transformative solutions. 
2. Understand, develop, and demonstrate innovative dissipative/detached divertor solutions for power exhaust and particle control sufficient for extrapolation to steady-state reactor conditions.

3. Understand, develop, and demonstrate innovative boundary plasma solutions for main chamber wall components, including tools for controllable sustained operation, sufficient for extrapolation to steady-state reactor application.

4. Understand the science of evolving materials at reactor-relevant plasma conditions and how novel materials and manufacturing methods enable improved plasma performance.

5. Understand the mechanism by which boundary solutions and plasma-facing materials influence pedestal and core performance and explore routes to maximize fusion performance.

The five priority research directions will address three underlying challenges/themes for PMI: (1) power exhaust and the plasma core/boundary compatibility, (2) PFC lifetime, and (3) tritium retention.

\subsection{MAJOR TECHNICAL CHALLENGES}

\subsubsection{Power Exhaust}

One of the primary functions of PFCs is to exhaust the power leaving the core plasma. Current technologies are capable of exhausting heat fluxes of up to $10 \mathrm{MW} / \mathrm{m}^{2}$ [9]. Tungsten-based PFCs may be restricted to $5 \mathrm{MW} / \mathrm{m}^{2}$ in the reactor environment [10], and increasing this level using low-activation materials as required in a neutron environment is an active research area [11]. Radiative dissipation will be used to maintain the heat flux at $<10 \mathrm{MW} / \mathrm{m}^{2}$ for ITER; this corresponds to a parallel plasma heat flux of $40-80 \mathrm{MW} / \mathrm{m}^{2}$ (Note, the divertor also receives heating from radiation and neutral particles.). Because the power-handling capability of the PFC will be similar in a reactor, or even more restricted, similar perpendicular and parallel heat fluxes at the target must be achieved. To develop heat exhaust technologies under reactor-relevant conditions, heat fluxes of $\sim 5-10 \mathrm{MW} / \mathrm{m}^{2}$ perpendicular to the PFC surface or $\sim 40-80 \mathrm{MW} / \mathrm{m}^{2}$ parallel to the magnetic field are desirable. Reducing and controlling the heat flux in a tokamak divertor to this level is the subject of active research. A measure of the challenge is the parameter $P / R$. It was found that the radial power decay length $\left(\lambda_{\mathrm{q}}\right)$ in the scrape-off-layer (SOL) scales independently of device size [12]. It depends solely on the poloidal magnetic field strength. Hence the power flux to the divertor PFC scales with the power into the SOL divided by the major radius.

Future devices might have a shorter radial decay length because of their larger poloidal magnetic field, but not by much. Although today's large tokamaks have magnetic fields up to 4 T, future devices are projected to have magnetic fields of 5-7 T. Note that the scaling obtained from multiple devices was performed for strongly attached plasmas. Currently it is not clear how much the power decay length will be spread out by radial transport and radiative dissipation on the target. However, it is clear that charge exchange processes lead to power spreading in the divertor, and for low electron temperatures $\left(T_{\mathrm{e}}<2 \mathrm{eV}\right)$ at higher electron densities, three-body recombination becomes nonlinear more efficient, leading to dissipation and power spreading. This is an ongoing topic of research.

Table 1 summarizes the power exhaust challenges for future devices like PPCS A [13], ARIES-ACT1 [14], and ITER [15]. In addition, two strongly heated discharges from the Joint European Torus (JET) [16] and ASDEX Upgrade (AUG) [17] are shown in which most of the heating power was dissipated by radiation through impurity seeding. 
Table 1. Comparison of figures of merit for power exhaust and power dissipation among future reactor studies (PPCS A, ARIES-ACT1), ITER, and high-power discharges on JET and AUG.

\begin{tabular}{|l|c|c|c|c|c|}
\hline & PPCS A & ARIES-ACT1 & ITER & JET & AUG \\
\hline $\mathrm{P}_{\text {heat }}[\mathrm{MW}]$ & 1246 & 405.7 & 123 & 33 & 23 \\
\hline $\mathrm{P}_{\text {heat }} / \mathrm{P}_{\mathrm{LH}}$ & 4.5 & 3.7 & 1.36 & 3.4 & 6.7 \\
\hline $\mathrm{P}_{\text {heat }} / \mathrm{R}[\mathrm{MW} / \mathrm{m}]$ & 130 & 65 & 19.8 & 11.4 & 14 \\
\hline $\mathrm{f}_{\text {rad }}^{*}$ wo br, syn rad & 0.64 & 0.67 & 0.54 & 0.76 & 0.87 \\
\hline $\mathrm{P}_{\text {heat }}^{*} / \mathrm{R}[\mathrm{MW} / \mathrm{m}]$ & 93 & 51 & 15 & 11.4 & 14 \\
\hline $\mathrm{P}_{\text {heat }}^{*} \mathrm{~B} / \mathrm{R}[\mathrm{MW} \mathrm{T} / \mathrm{m}]$ & 651 & 306 & 80 & 39 & 35 \\
\hline $\mathrm{P}_{\mathrm{LH}} \mathrm{B} / \mathrm{R}[\mathrm{MW} \mathrm{T} / \mathrm{m}]$ & 202 & 105 & - & - & - \\
\hline$\beta_{\mathrm{N}}$ & 3.5 & 4.75 & 1.77 & 1.6 & 3 \\
\hline $\mathrm{H}_{98(\mathrm{y}, 2)}$ & 1.2 & 1.65 & 1 & 0.71 & 1.0 \\
\hline
\end{tabular}

It becomes immediately apparent in Table 1 that the unmitigated heat fluxes toward the divertor will increase by a factor of 10 , when one compares PPCS A and AUG achieved $P / R$ values. The obvious question is how much of that heating power can be dissipated by impurity radiation. For that reason, it is better to compare the $P / R$ without bremsstrahlung and synchrotron radiation $\left(P^{*}\right.$ heat $\left./ R\right)$. The challenge is then not that severe with a factor of about 7 between AUG and PPCS A. In AUG the heat fluxes were reduced below $5 \mathrm{MW} / \mathrm{m}^{2}$ in those discharges [17]. It should be noted that most of the radiation is not in the SOL. As observed in several devices $[18,19]$, the impurity radiation originates from the main chamber as well. A maximum of $P_{S O L} / R$ of about $7 \mathrm{MW} / \mathrm{m}$ was achieved in AUG [17]. This should be compared with a $P_{S O L} / R \sim 12 \mathrm{MW} / \mathrm{m}$ for ITER. However, considering that the magnetic field, and in particular the poloidal magnetic field, in ITER $\left(B_{t}=5.3 \mathrm{~T}\right)$ is about a factor of 2 higher than in AUG $\left(\mathrm{B}_{\mathrm{t}}=\right.$ $2.5 \mathrm{~T}$ ), the power decay length at the midplane in the SOL is expected to be a factor of 2 shorter in ITER, assuming that the magnetic field configurations and $\mathrm{q}_{95}$ are similar for ITER and AUG. This would enhance the maximum heat flux at the target by a factor of 2 . This is reflected in the $P^{*}$ heat $B / R$ in Table 1 , which is about a factor of 2 higher in ITER than in JET or AUG. Spreading of the power due to radiation and CX neutrals might reduce this difference. In AUG, even for $P_{S O L} / R$ of about $10 \mathrm{MW} / \mathrm{m}$, the heat fluxes in the divertor are below $5 \mathrm{MW} / \mathrm{m}^{2}$, whereas $10 \mathrm{MW} / \mathrm{m}^{2}$ are projected for ITER. Hence, within the uncertainties of the power spreading due to radiation and CX neutrals, the power dissipation in the SOL (from midplance to divertor) in AUG is similar to that in ITER.

For devices beyond ITER, a significant part of the power must be radiated from the plasma core. For PPCS A as well as ARIES-ACT1, the power over the LH-threshold power is significantly higher, potentially allowing for significant plasma core radiation of about $70 \%-80 \%$. Assuming most of the power can be radiated in the core without impact on confinement so that $P_{S O L}=P_{L H}, P_{L H} B / R$ (Table 1) would be reduced to about $100 \mathrm{MW} \mathrm{T/m}$ and $200 \mathrm{MW} \mathrm{T} / \mathrm{m}$ for ARIES-ACT1 and PPCS A, respectively. For ARIES-ACT1 this would be only slightly above the ITER values. Recently AUG has demonstrated plasma core radiation of up to $70 \%$ without loss of confinement [17]. There is concern, however, that significant plasma core radiation might influence the core confinement. Experiments on AUG [20] and JET [21] have shown that the confinement enhancement factor $H_{98(y, 2)}$ scales with the normalized plasma pressure $\beta_{N}$. This gives some hope that in high $\beta_{N}$ operation, as predicted for PPCS A and ARIES ACT1, the confinement could be better than 1 . In addition, seeding of nitrogen has been shown to actually improve the confinement of plasmas [22]. Despite the $\beta_{N}$ scaling and the impurity effect on core confinement, it is uncertain if a high $H_{98(y, 2)}$ of 1.2 or 1.6 can be reached with a strongly radiating mantle and plasma core. Plasma core confinement simulations for those highly radiating reactor plasmas are necessary for actual predictions. 
In case radiative dissipation of the heat fluxes is insufficient, an advanced divertor configuration will further help to distribute the power. This can be achieved by either increasing the number of strike points with the so-called snowflake configuration [23], increasing the poloidal flux expansion with the Xdivertor [24], increasing the parallel connection length in the SOL and moving the strike point to a larger radius with the Super-X-Divertor [25], or combining these approaches [26]. However, it should be noted that if most of the power is radiated away in the plasma core, the challenges for power exhaust are not as severe as the following challenges for the PMI (Figure 1). Table 1 also illustrates the challenge for the power dissipation very much depends on the concept of the next-generation device. Although it is challenging to extrapolate from today's experiments to a PPCS A type device, the challenge of power exhaust is lessened in a device like ARIES-ACT1. Data on power dissipation from ITER will certainly help power plant design. Should innovation take place, and high temperature superconducting magnets will be used in future fusion reactors, the power dissipation problem will be excerberated. Hence, the need to study power exhaust in a dedicated divertor tokamak test facility very much depends on the vision of a future fusion reactor.

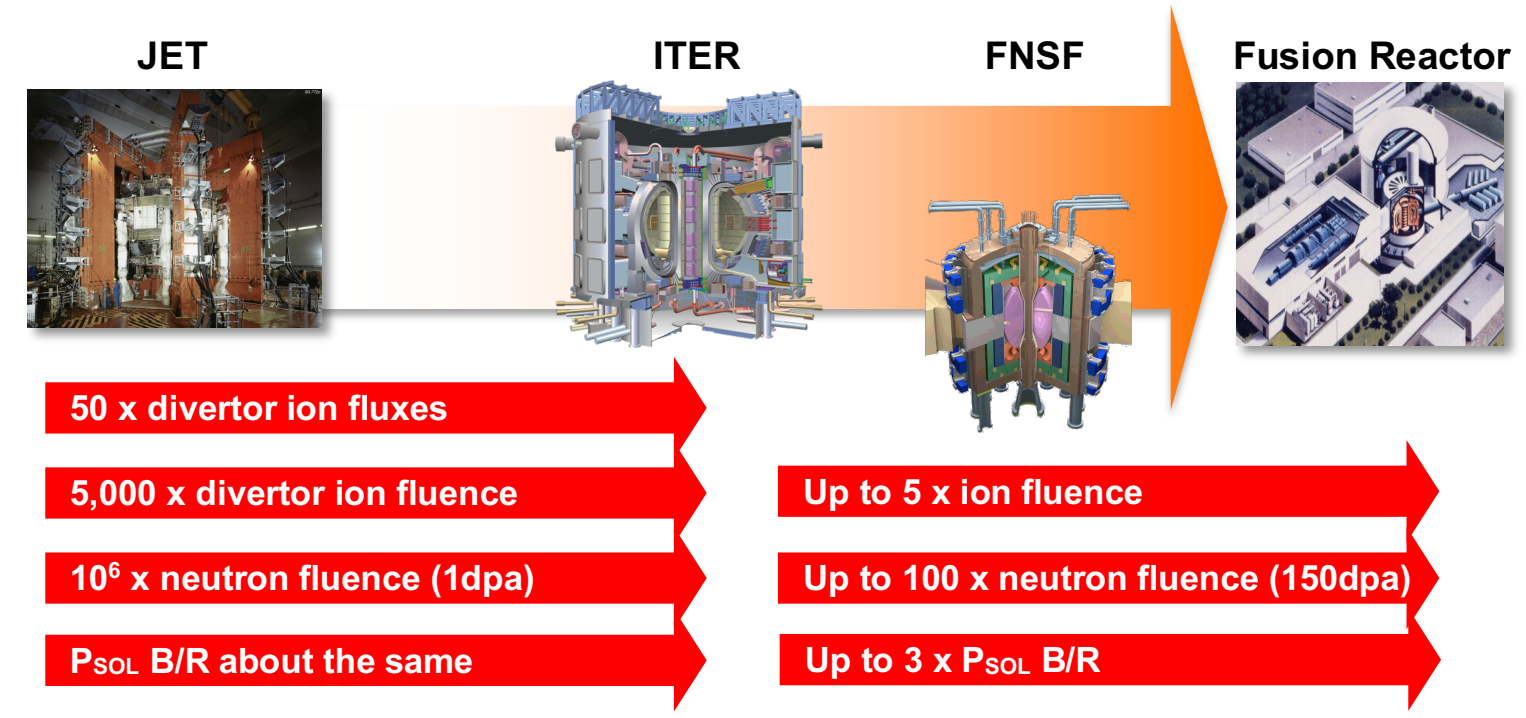

Figure 1. Challenges for PMI in fusion reactor divertors as they increase from today's largest fusion device JET to ITER and then via FNSF to a fusion reactor.

\subsubsection{Plasma-Facing Component Lifetime}

In addition to large heat fluxes, the divertor is exposed to high ion fluxes $\left(\Gamma>10^{24} \mathrm{~m}^{-2} \mathrm{~s}^{-1}\right)[27]$ and fluence, which lead to erosion and redeposition as well as surface layer modifications. These processes depend strongly on both the material composition and on the plasma characteristics near the PFC surface. Taking the ITER divertor scenario as an example, conditions vary from a "detached," cold $\left(T_{\mathrm{e}} \sim 1 \mathrm{eV}\right)$, and very dense $\left(n_{\mathrm{e}}>2 \times 10^{21} \mathrm{~m}^{-3}\right)$ plasma at the strike point to a hotter $\left(5<T_{\mathrm{e}}<20 \mathrm{eV}\right)$ "attached" plasma with reduced density $\left(10^{19}<n_{\mathrm{e}}<10^{21} \mathrm{~m}^{-3}\right)$ a short distance into the SOL. The detached strike point region is expected to be one of net deposition (because physical sputtering is minimal), leading to surface morphology changes with uncertain consequences. Although the lack of net erosion at these plasma parameters may be attractive from the point of view of PFC lifetime, the deposition in this region will change the surface morphology in a nonlinear way and lead to changes (surface area, temperature distribution, chemical activity, etc.) and the potential release of dust particles. The attached region is expected to be a net erosion zone, which would limit the PFC lifetime. In a reactor with tungsten PFC, the net erosion yield must be lower than $10^{-6}$. Realistic solutions will require a significant amount of prompt redeposition of the eroded ions to ensure this net erosion rate at those electron temperatures. 
In addition to the inter-ELM erosion, edge localized modes (ELMs) will significantly contribute to the erosion. On JET the tungsten erosion in the divertor is dominated by ELMs; up to 80\% of the tungsten source is from ELMs [28]. The source per ELM strongly correlates with the energy loss by the ELM. Although inter-ELM tungsten erosion is determined by the physical sputtering of light impurities, physical sputtering by deuterium is more important during the ELM [28].

Physical sputtering is not the only tungsten erosion process. The high ion fluxes (hydrogenic, helium, and impurities) together with the heat fluxes will alter the surface microstructure and its morphology. This might lead to a source of macroscopic erosion. High deuterium pressures will lead to blister formation [29] that can ultimately lead to whole grain ejections [30] if thermal stress is applied by thermal cycling. Tungsten nanostructure extrusions, so-called "fuzz" [31], can be a source of dust when unipolar arcing occurs [32]. Melting might occur if the heat fluxes are too high, potentially leading to melt-layer splashing, which will create micrometer-sized tungsten dust [33]. Similarly, transients like ELMs will modify the material structure. It has been found that ELMs will change the grain size [34]. In addition, helium will reduce the thermal conductivity [35], which will have consequences on the tolerable ELMinduced temperature excursions. All of these effects will impact the allowable ELM size and are the subject of active research.

Radio-frequencey (RF) wave launchers, which must sit close to the plasma, for heating, current drive, or both are effectively PFCs with large applied RF potentials forming sheaths, which can enhance erosion of antenna PFCs. Therefore, to study the relevant erosion/redeposition physics, a PMI facility must be able to access a wide range of plasma parameters covering both the attached and detached PFC regions, implying $1<T_{\mathrm{e}}<20 \mathrm{eV}$ and RF-induced sheaths.

\subsubsection{Tritium Retention}

Control of the tritium inventory is crucial for the sake of both safety [36] and fuel economy [37]. For tungsten, retention is determined mainly by the hydrogenic inventory in the bulk material (in contrast to low- $Z$ materials where the inventory is dominated by codeposition with the eroded material [36]). The diffusion and permeation of hydrogenic species within the bulk material are strongly temperature dependent [36]; thus, it is important to investigate retention in the temperature range of future fusion reactors. Furthermore, retention depends strongly on the fluence, and experimental data is at present limited to $10^{27}-10^{28} \mathrm{D} / \mathrm{m}^{2}$. Some of these measured values give some indication of saturation at the highest achieved fluences. However, recent experiments done on PISCES [38] indicate that the deuterium retention in tungsten is not saturating and follows a $\mathrm{t}^{0.5} \mathrm{scaling}$. To eliminate any uncertainties with respect to projections for future fusion reactors, experiments substantially beyond the $10^{28} \mathrm{D} / \mathrm{m}^{2}$ fluence level are needed. Finally, it is expected that hydrogen will also be trapped in neutron-produced trap sites, indicating the need to study the retention properties of irradiated samples.

The challenges for the plasma-facing materials and components are related to the divertor ion fluxes, divertor ion fluence, and neutron fluence (or damage level by neutrons, i.e., displacements per atom). In addition, the challenge to mitigate the heat flux in the plasma boundary is shown as a function of power into the SOL times the magnetic field divided by the major radius of the device (this quantity gives a good normalization for the scaling of divertor heat fluxes between tokamaks of different sizes).

\subsection{MAJOR SCIENCE CHALLENGES}

To address the technical challenges described above, advancement in specific areas of science is needed. These challenges range from plasma-surface interaction dynamics to plasma physics and are closely related to other scientific and technical disciplines. Figure 1 gives an overview of the challenges related to ion fluxes to the divertor, divertor ion fluence, and neutron fluence. The challenge of power exhaust is 
highlighted in Figure 1 too, but it is not further discussed in the context of addressing research and development gaps in plasma-material interactions with linear devices.

\subsubsection{HIGH FLUXES}

The high flux regime might lead to nonlinear behavior in the erosion mechanism. Physical erosion can perhaps be minimized by cooling the plasma before it encounters the material surface. Chemical erosion by hydrogen will be the dominant erosion mechanism for some plasma-facing materials, but precisely the chemistry might be different at those high fluxes. For carbon-based materials, a reduction in the chemical erosion yield with increasing ion flux density is predicted [37]. Exposing materials such as refractory metals with intrinsically low hydrogenic solubility to high hydrogen fluxes might lead to supersaturation of hydrogen in the ion implantation zone of the surface (about $10 \mathrm{~nm}$ below the surface) [39]. This supersaturation might lead to dislocations of lattice atoms and create damage effects in the crystal, thereby leading to potentially high hydrogenic retention in the material. The high fluxes might also have an impact on the changes in surface morphology, just because the transfer of impurities from the plasma to the surface is increased and stronger deposition of impurities is occurring. However, the sub-surface damage also depends strongly on the ion flux. While low ion fluxes lead to a few very large blisters, high ion fluxes $\left(>10^{24} \mathrm{~m}^{-2} \mathrm{~s}^{-1}\right)$ show many small blisters together with protrusions [40]. Recently hydrogenic retention measurements at very high fluxes in plasmas with low electron temperature and high density, prototypic for a partially detached divertor plasma in ITER, showed the formation of a chemisorbed protective layer [41]. This layer leads to strongly reduced penetration of atomic deuterium in radiationdamaged tungsten, reducing the retention by several orders of magnitude. This shows the importance of investigating the effect of high fluxes with relevant (low) ion energies.

\subsubsection{HIGH FLUENCE AND THE RELATED INCREASE IN COMPLEXITY OF THE STRONGLY EVOLVING SURFACES}

In addition to the high flux exposure, the plasma-material system under these extreme conditions is characterized by its complexity. The solid is strongly coupled to the plasma. In metals, complexity is increased by the possible development of a liquid layer, which is exposed not only to the plasma pressure but also to strong electromagnetic forces. These so-called multiphase plasma-material systems are extremely complex. In this regime of strongly coupled plasma-surface interactions, the mean-free path of the erosion products is smaller than the typical scale length of the system. This essentially means that the erosion products are trapped in the plasma and return to the surface in a modified form. Hence, the plasma-surface interaction determines the plasma composition in front of the target and has a local feedback effect on the plasma-surface interactions. This feedback effect will strongly modify the surface morphology in a nonlinear way. The surface morphology is characterized by multiscale dimensional changes. A rich variety of nanostructures are being observed: nanotubes, nanospheres, and nanopillars $[42,43]$. The variation in size is often very small and depends on the magnetic field. In addition, larger cauliflower-like structures form that grow to several micrometers in size in irregular ways. These structures can become so large that they eventually even peel off during transient power flux excursions. Surface morphology changes in tungsten (so-called tungsten fuzz) have been observed as a result of the exposure of helium plasmas at high temperatures [44]. Those nanostructures can also delaminate [45] (because of unipolar arcing, for example) and possibly create nanometer-size tungsten dust. The confined tungsten dust may then return to the surface and change its surface morphology.

The stability of these surface layers and nanostructures is of utmost importance because it determines large-scale erosion processes, which should be avoided as much as possible because they can have very detrimental effects on the plasma core performance of a fusion device due to instantaneous release of a large particle source. The erosion of the deposited surfaces will be altered due to the morphology of the surface and the composition of the surface layers. Thermally loosely bound deposition layers or other 
surface morphology changes (tungsten-fuzz, blisters, protrusions, helium bubbles) might have increased surface temperatures due to thermal conductivity changes, which will change erosion yields and might lead to melting. Increased roughness will increase the surface area, possibly effectively lowering ion flux densities to the surface, which could affect the chemical erosion yield of carbon for example. However, it is not clear how the plasma will interact with surface areas which are not in direct line-of-sight in those complex 3-D nanostructures. Understanding of the fundamental processes leading to the formation of these complex structures might provide details about how changes in surface morphology can be controlled by acting on the plasma parameters or their composition in front of the surface. In addition, the findings from surface morphology changes might even give insight into the self-organized assembly of complex structures, which could possibly lead to equilibrium via self-passivation or self-healing processes.

\subsection{3 “COLD” HIGH-DENSITY PLASMA}

In addition to the rich field of plasma-surface interactions, the plasma physics itself will be different. Under conditions expected in future fusion divertor plasmas at densities several times greater than $10^{21} \mathrm{~m}^{-3}$ and at low plasma temperatures of $1 \mathrm{eV}$ or even less, the divertor plasma is close to the strongly coupled limit, where the kinetic energies are in the same range or lower than the interaction potential energies. This has a considerable impact on the plasma chemistry and atomic physics. Understanding these processes in the strongly coupled regime is difficult and requires further investigation. And understanding the consequences of this physics and chemistry is necessary for the interpretation of the optical emission spectroscopy in fusion reactor-grade divertor plasmas. This has connections to other fields of science where similar strongly coupled plasmas are found [46]. In these strongly coupled plasmas with Debye length of $100 \mathrm{~nm}$ or less, large angle Coulomb scattering will become more important and must be considered in divertor plasma modeling.

Radiation transport will play a larger role. The plasma will be optically thick, which greatly affects the overall transport and energy balance. It has a particularly strong effect on highly radiating, partially detached divertor plasmas and can also significantly affect the plasma detachment process. Consequently, a fundamental understanding of radiation transport in those high-density plasmas is necessary. The formation of dust in suspension is much more likely. This regime will open the vast physics of such dusty plasmas, which includes the charging of dust grains and dust dynamics under the influence of various forces, as well as collective interactions such as waves and instabilities. The dust particles introduce vastly different length scales into the problem of plasma-surface interactions. Several assumptions of basic plasma physics are violated. The Debye screening length losing its meaning is only one example that will complicate the theory and understanding of those plasmas. This work is beneficial not only to nuclear fusion applications but also to general dusty plasma research and materials synthesis. In the divertor plasma, dust particles are confined by the magnetic field. The system size and the magnetic field strength will determine the concentration and maximum size of the dust particles. Their growth rate, in the relevant size range, scales approximately quadratically with their concentration. The generated dust in suspension will, of course, interact with the material surface and be deposited, thereby adding to the complexity of the surface morphology in this regime.

\subsubsection{NEUTRON IRRADIATION DAMAGE}

Neutron irradiation of PFCs will strongly affect their performance in a progressive manner. It will reduce their thermal conductivity to the extent that some materials will not be able to exhaust the high-power fluxes of $10-20 \mathrm{MW} / \mathrm{m}^{2}$. In addition to the ion implantation at low and medium energies, transmutation will change to the chemical composition of the material (Table 2). This will have consequences in the form of helium and hydrogen isotope accumulation. In the fusion environment $14 \mathrm{MeV}$ neutrons produce 100 times more helium per dpa when compared to fission neutrons [47]. This will result in 
microstructural changes in the material, leading to swelling and possibly blister formation. This could, on the one hand lead to enhanced erosion, and on the other to reduced thermal contact and misalignments and hence reduced power handling. The mechanical properties will be influenced by changes in the DBTT (ductile-brittle transition temperature directly, and by indirect changes in the DBTT due to modifications in the chemical composition (e.g., changing the alloying composition due to transmutation) $[47,48]$. Altogether these changes could minimize the operation window for an acceptable surface temperature of the plasma-facing materials. Neutron irradiation will lead to interstitials and vacancies and their associated clusters, dislocation loops, and voids [49-51]. These damaging mechanisms will increase the tritium inventory in the plasma-facing materials [52-56]. The dynamics (mobility and clustering) of the interstitials and vacancies will depend on the temperature, as does the diffusion/permeation of tritium. Understanding the mobility and clustering of the damage sites as well as the trapping and detrapping of hydrogen at elevated temperatures, including temperature excursions during transient events of several $\mathrm{GW} / \mathrm{m}^{2}$ during a millisecond like ELMs, is a challenge.

Table 2. Irradiation damage and consequences for PMI.

\begin{tabular}{|l|l|}
\hline \multicolumn{1}{|c|}{ Neutron irradiation damage } & \multicolumn{1}{c|}{ Consequences for PMI } \\
\hline Thermal conductivity & $\begin{array}{l}\text { Reduced temperature operation window, less tolerance to } \\
\text { transient heat loads, erosion yield }\end{array}$ \\
\hline Chemical composition (transmutation) & $\begin{array}{l}\text { Hydrogen retention, thermal conductivity indirectly (see } \\
\text { above) }\end{array}$ \\
\hline $\begin{array}{l}\text { Interstitials, vacancies, dislocations, and } \\
\text { voids }\end{array}$ & Hydrogen retention \\
\hline Microstructural changes (swelling) & $\begin{array}{l}\text { Tolerance in PFC alignment will become larger, hence power- } \\
\text { handling capability lower }\end{array}$ \\
\hline Ductile-brittle transition temperature & Reduced temperature operation window \\
\hline He, H embrittlement & Erosion and dust production will be enhanced \\
\hline
\end{tabular}

The role of the grain size might play an important role in the understanding of the dynamics. Annihilation of vacancies at the grain boundary, transport of such trap sites across the grain boundaries in the presence of high hydrogen fluxes to the surface, and diffusion/permeation of it through the material are unexplored areas of science. How does the irradiation-induced damage move during stress? Answering this question could provide important information on the hydrogenic inventory during disruptions, where high thermodynamic and electromagnetic stresses occur. Although the damage rate due to plasma bombardment is several orders of magnitude greater than that due to neutrons, the lifetime of the PFC surface layer is limited in a net-erosion regime, so the accumulated damage between the two processes can be comparable (e.g., if the prompt redeposition rate is $99 \%$, then the surface will be made up of atoms that have been sputtered and redeposited $\sim 100$ times, which is comparable to the $\sim 50$ dpa neutron damage expected in a reactor). A linear device capable of handling irradiated materials would allow an early test of the potential synergy between neutron damage and PMI, which has been already demonstrated in measurements of erosion [57] and tritium retention [54] on irradiated samples. Furthermore, gaseous transmutation products like helium can change tritium transport in the material and have a strong impact on the tritium retention in metals like tungsten [58]. This would further reduce the risk to the design and operation of a full-scale Fusion Nuclear Science Facility. 



\section{DISCUSSION OF CURRENT AND NEAR FUTURE FACILITIES AND EXPERIMENTAL CAPABILITIES}

\subsection{CAPABILITIES OF EXISTING TOROIDAL DEVICES}

PMI has been a topic of research on fusion devices since the very beginning. Many toroidal devices were built with this main purpose in mind. Such devices were for example ORNL's Impurity Source eXperiment (ISX) and the Toroidal EXperiment for Technical Oriented Research (TEXTOR). Those devices mainly investigated the effect of the wall conditions on the quality of the main plasma. In those devices, many wall conditioning methods [59-62] were pioneered such as the carbonization, boronization, beryllium evaporation, siliconization, and medium-Z (titanium and chromium) gettering. These methods were subsequently utilized on all toroidal confinement devices around the world, and plasma-facing material choices were driven by the performance of the devices. Reference [63] gives a good overview of all wall conditioning methods. Early deployments of high- $Z$ materials in various tokamaks (e.g., ORMAK, Doublett-II, PLT) were not successful mainly due to high physical sputtering rates. Carbonbased PFCs had a success on PLT leading to higher core electron temperatures. After this success, most toroidal devices started using graphite or carbon fiber composite materials. This was until the Tokamak Fusion Test Reactor (TFTR) and JET found enhanced tritium retention due to strong codeposition with carbon in those devices, making carbon-based materials difficult for future use in reactors. Recent experiments on JET with an ITER-like wall made of beryllium in the main chamber and tungsten in the divertor demonstrated that tritium retention can be reduced by more than an order of magnitude [64].

Although many devices focused on the quality of the core plasma and edge-core compatibility, new plasma-facing materials and components have not been tested or developed. Some load-lock systems have been in place for testing material samples on devices such as the limiter load-lock system on TEXTOR, DIMES on DIII-D, MAPP on NSTX, MAPES on EAST, and many others.

The capabilities of selected toroidal devices to carry out a PMI research program are shown in Table 3. The DIII-D Upgrade, AUG, and EAST Upgrade should be able to contribute to emerging research on power exhaust because their $P / R$ is formidable, and their divertor size is large enough to be able to extrapolate to larger devices like ITER or DEMO. Most devices can test variable divertor geometries or upgrade their device to test alternative divertor geometries; however, the core-edge integration would require DEMO-like pedestals. Achieving these requires at least a medium-sized device plus high heating power and potentially a low-Z main chamber wall to ensure low collisionality in the boundary plasma. Only a few devices can meet these requirements. Note, the necessary upgrades to existing devices in form of novel divertor concepts and PFCs require high investment costs. 
Table 3. Ability of toroidal devices (national and international) to study fusion reactor-relevant power exhaust. The capabilities here include planned but not yet funded upgrades.

\begin{tabular}{|c|c|c|c|c|c|}
\hline Criteria & $\begin{array}{l}\text { DIII-D } \\
\text { Upg. }\end{array}$ & NSTX-PMI & $\mathbf{A U G}$ & $\begin{array}{l}\text { MAST } \\
\text { Upg. }\end{array}$ & $\begin{array}{l}\text { EAST } \\
\text { Upg. }\end{array}$ \\
\hline $\begin{array}{l}\mathrm{P} / \mathrm{R}>>20[\mathrm{MW} / \mathrm{m}] \\
\mathrm{q} / /\left[\mathrm{GW} / \mathrm{m}^{2}\right]\end{array}$ & $\begin{array}{c}25 \\
1\end{array}$ & $\begin{array}{l}17 \\
0.2\end{array}$ & $\begin{array}{c}16 \\
1\end{array}$ & $\begin{array}{c}9+ \\
0.07\end{array}$ & $\begin{array}{c}20 \\
2\end{array}$ \\
\hline $\mathrm{n} \times \mathrm{L}($ or $\mathrm{R})$ & $1 / 3$ & - & $1 / 4$ & - & $1 / 3$ \\
\hline Wall, divertor $\mathrm{T}[\mathrm{K}]$ & Room T & 700 & Room T & Divertor 500 & 800 \\
\hline Divertor concepts & $\mathrm{C}, \mathrm{SF}, \mathrm{LV}$ & $\mathrm{C}, \mathrm{SF}$ & $\mathrm{C}$ & $\mathrm{C}, \mathrm{SF}, \mathrm{SXD}$ & $\mathrm{C}$ \\
\hline DEMO-like pedestal & $\mathrm{Y}$ & $\mathrm{N}$ & $\mathrm{N}$ & $\mathrm{N}$ & $\mathrm{N}$ \\
\hline Pulse length $[\mathrm{s}]$ & 5 & 10 & 5 & 5 & 1,000 \\
\hline Wall material & $\mathrm{C}$ & W, Li, Ga, Sn & $\mathrm{W}$ & $\mathrm{C}$ & $\mathrm{W}, \mathrm{Li}$ \\
\hline $\begin{array}{l}\text { Material test load-lock } \\
\text { system }\end{array}$ & Yes & Yes & Yes & No & Yes \\
\hline
\end{tabular}

Abbreviations: Conventional divertor (C), snowflake divertor (SF), long vertical target divertor (LV),

Super-X-Divertor (SXD). Note: Wall materials are C, W, Li, Ga, and Sn.

Only a few toroidal devices have an all-metal inner wall. Most devices have graphite or carbon fiber composite PFCs, such as DIII-D, NSTX in its current configuration, MAST upgrade, KSTAR, W7-X, LHD, and JT-60SU. All-metal devices are AUG, EAST, and JET. This can influence the materials they can test in their devices. Most of the devices are short pulse devices and therefore do not require actively cooled PFCs. Also, the ambient wall temperature in most cases is room temperature or a little higher for wall conditioning purposes. For example, JET has a $500 \mathrm{~K}$ wall temperature. Only the EAST Upgrade (and possibly NSTX-PMI) plan to increase the wall temperature to 700 or $800 \mathrm{~K}$.

\subsection{LIMITATIONS OF EXISTING TOROIDAL DEVICES}

\subsubsection{Divertor Ion Flux}

Only in high field devices, like Alcator C-mod for example, were high ion fluxes similar to ITER-like divertor conditions $\left(>10^{24} \mathrm{~m}^{-1} \mathrm{~s}^{-1}\right)$ achieved $[65,66]$. All other tokamaks can only reach ion fluxes in the order of $10^{22} \mathrm{~m}^{-2} \mathrm{~s}^{-1}$ to $10^{23} \mathrm{~m}^{-1} \mathrm{~s}^{-1}$.

Long pulse tokamaks usually operate at lower heating powers, lower plasma current, and lower plasma density to achieve long pulses. This is mainly because the current state-of-the-art RF heating systems do not allow for high-power densities in long pulses. Steady-state neutral beam injectors are not even available. To increase the current drive efficiency, tokamaks operate at lower plasma current and density. This decreases the ion fluxes in the divertor in long pulse operation.

\subsubsection{Divertor Ion Fluence}

Current pulsed tokamaks accumulate a fluence of $\sim 10^{25} \mathrm{~m}^{-2} / \mathrm{y}$, which is approximately 5 orders of magnitude below what is needed. Superconducting long pulse tokamaks and stellarators achieve longer pulse durations; however, their fluxes are usually lower (for reasons, see above). In addition, many tokamaks and stellarators only analyze their plasma-facing components after lengthy experimental campaigns. Hence many data available for toroidal devices are campaign-averaged data, meaning that data are averaged over different conditions tokamaks are enduring in short duration, like inter-ELM phases, ELM phases, L-mode phases, ramp-up in different operation scenarios for many campaigns, venting, and more. For example, experiments have shown that hydrogen retention being determined by 
gas balance measurements during individual discharges can differ strongly from being determined after postmortem ex-situ analysis of materials. In the case of the ITER-like wall, the discrepancy was a factor of 10-20 [64,67], and in the case of Alcator C-mod, the discrepancy was a factor of 1,000 [68]. The same is true for erosion data [69], where only a few high-power, high-divertor $T_{\mathrm{e}}$ discharges can determine the erosion yield of a whole campaign. Load-lock systems can sample data for individual pulses and even time durations within a pulse, but the fluence accumulated will be extremely low in this case.

\subsubsection{Electron Density and Electron Temperature in Front of PFCs (Divertor or Limiter)}

Electron temperatures in front of the target can be as high as $100 \mathrm{eV}$ in limiter configurations and as low as $1 \mathrm{eV}$ or less in a high-density, partially detached divertor configuration. A large database for many electron temperatures already exists. However, except for Alcator C-mod, no tokamak has ever reached electron densities of $10^{21} \mathrm{~m}^{-3}$ in front of the target as they are predicted for the partially detached divertor regime in ITER. Even in Alcator C-mod, densities in this range were measured in a MARFE-like highdensity region, not directly in front of the target but a little further upstream [66].

\subsubsection{ELM Heat Fluxes}

Other than JET, tokamaks cannot reach subcritical ELMs with heat fluxes of about $1 \mathrm{GW} / \mathrm{m}^{2}$ as they might occur in ITER as mitigated ELM heat fluxes. This is mainly because the ELM energy loss scales with the total stored energy and hence the machine size. And even in JET, pulses with an ELM energy loss of $1 \mathrm{MJ}$ were run in a carbon wall environment at high current at low ELM frequencies of about $1 \mathrm{~Hz}$. This regime is likely not possible anymore in the ITER-like wall configuration on JET. In addition, since the plasma fluxes are much lower in the current toroidal devices than expected in ITER, the resulting forces on potential melt layers are not the same.

\subsubsection{Ambient Temperature}

The ambient temperature of the existing devices is mostly room temperature. Only a few devices were designed to have larger ambient temperature (e.g., JET). Introducing a hot wall is not an easy task.

Normally, devices must be designed to cope with the hot wall environment. Also, many effects of the hot wall, like recycling of the hydrogen which is determined by the temperature of the main chamber wall, is not in equilibrium in short pulse devices.

\subsubsection{Testing of New Materials}

Testing of new materials is either a large upgrade project of the whole device or restricted to materials sample tests in load-lock systems. The disadvantage of introducing a new material in a load-lock system is that it is embedded in a wall with a potentially different elemental composition. This will make analysis of the PMI difficult because erosion products from the walls in the device will erode the material sample, deposit on the material sample, or both. This complicates many aspects of the material properties like hydrogen retention (due to codeposition), erosion yields (due to surface deposition of main chamber wall elements on the material sample) [70], surface evolution (due to deposits), chemical composition changes, and many more. A clean experiment is difficult to perform in this environment.

\subsubsection{Test of Neutron-Irradiated Samples}

Today's tokamaks do not generate enough neutrons to effectively test materials. Even for materials in ITER, which will be the worlds most aggressive confinement environment to date, the expected lifetime neutron displacement damage will only be $1 \mathrm{dpa}$. This is at least an 1 order of magnitude lower than what is expected in future fusion power reactors. No device is designed to introduce a priori neutron-irradiated 
materials to expose them to a fusion plasma. Hence, a test of neutron-irradiated plasma-facing materials is not possible in toroidal devices.

\subsubsection{End-of-Life Tests of Plasma-Facing Components}

Toroidal devices cannot conduct reactor-relevant end-of-life studies for PFCs. This is true even for long pulse devices like KSTAR, EAST, WEST, LHD, and W7-X. There are many reasons for this:

- Campaign-averaged divertor ion fluxes are typically a factor of 100 below reactor-relevant divertor ion fluxes in short pulse devices like AUG for example [69]. This might also be the case for a long pulse device as indicated above.

- Campaign-averaged net-erosion yield is factor of 100 above the reactor requirements in short pulse devices like AUG [69].

- Melt-layer loss can lead to disruptions and prematurely terminate the end-of-life experiment of the PFC.

- Release of dust can lead to disruptions and prematurely terminate the end-of-life experiment of the PFC.

\subsubsection{Availability of Toroidal Devices for PMI Research}

Research objectives for tokamaks and stellarators rely on the success of materials to withstand damage, yet only a fraction of research time is allocated to active PMI research. In addition, damage and lifetime studies of PFCs in tokamaks and stellarators are mostly not allowed or discouraged due to excessive risks and expenses (change of wall components; shutdown times) and issues of reactor relevance.

\subsection{CAPABILITIES OF EXISTING LINEAR DEVICES}

Much of the needed PMI studies and PFC development could be performed in a simplified geometry (i.e., in linear plasma devices) if the needed plasma parameters can be reached (see Table 4 for a comparison of US linear devices with tokamaks). These devices offer a much-reduced operational cost compared to tokamak operation, with better diagnostic access and dedicated experimental time for PMI/PFC studies. The prospects of operating linear plasma devices in near steady state to perform tests at reactor-relevant ion fluences are also much better than for tokamaks. Such a device would allow rapid evaluation and the development of combinations of PFC designs and plasma conditions that satisfy the requirements listed above. Development of PFCs beyond the divertor components would also be enabled, such as studying particle-antenna interactions and improving RF launcher design. Testing in tokamaks will be necessary as well, especially to ensure that the PFC and divertor plasma operation are compatible with core performance. High-power tokamak experiments will also be needed to develop methods for producing the plasma conditions at the PFC surface that are needed for satisfactory PFC operation. This includes controlling the divertor plasma temperature and reducing the heat flux from the $\mathrm{q}_{\|} \sim \mathrm{GW} / \mathrm{m}^{2}$ expected upstream to manageable levels of $\sim 5-10 \mathrm{MW} / \mathrm{m}^{2}$ perpendicular to the surface, which translates to plasma power loads of about $40-80 \mathrm{MW} / \mathrm{m}^{2}$ parallel to the magnetic field. (The plasma power loads are only a fraction of the total heat fluxes, which consist of plasma, radiation, and neutral power fluxes.) However, these issues can be addressed in short pulse tokamaks because they involve plasma transport timescales that are typically on the order of seconds or faster. 
Table 4. Comparison of linear and toroidal devices.

\begin{tabular}{|c|c|c|c|c|c|}
\hline & TPE & PISCES & Magnum & $\begin{array}{c}\text { Short pulse } \\
\text { tokamaks }\end{array}$ & $\begin{array}{c}\text { SC long pulse } \\
\text { tokamaks }\end{array}$ \\
\hline $\begin{array}{l}\text { Steady-state high-power flux to } \\
\text { target }\left[\mathrm{MW} / \mathrm{m}^{2}\right]\end{array}$ & $\sim 1$ & $\sim 10$ & $>10$ & $\mathrm{~N} / \mathrm{A}$ & N/A \\
\hline $\begin{array}{l}\text { Steady-state high-power plasma } \\
\text { flux on tilted ( } 5 \text { degree) target } \\
{\left[\mathrm{MW} / \mathrm{m}^{2}\right]}\end{array}$ & $\begin{array}{l}\mathrm{N} / \mathrm{A} \\
\text { (always } \\
\text { biased } \\
\text { target) } \\
\end{array}$ & $\begin{array}{c}\mathrm{N} / \mathrm{A} \\
\text { (always } \\
\text { biased } \\
\text { target) }\end{array}$ & $\begin{array}{c}\mathrm{N} / \mathrm{A} \\
\text { (source } \\
\text { limitations) }\end{array}$ & $\mathrm{N} / \mathrm{A}$ & $>3$ \\
\hline Target $T_{\mathrm{e}}, T_{\mathrm{i}}[\mathrm{eV}]$ & $\begin{array}{l}\text { N/A (no } \\
\text { thermal } \\
\text { plasma) }\end{array}$ & $\begin{array}{l}\text { N/A (no } \\
\text { thermal } \\
\text { plasma) }\end{array}$ & $<5$ & $3-50$ & $?$ \\
\hline Target $n_{e}\left[\mathrm{~m}^{-3}\right]$ & $<10^{18}$ & $<10^{19}$ & $10^{22}-10^{19}$ & $<10^{21}$ & $<10^{21}$ \\
\hline Reactor-relevant ion flux $\left[\mathrm{m}^{-2} \mathrm{~s}^{1}\right]$ & $<10^{22}$ & $10^{23}$ & $10^{25}$ & $<10^{23}$ & $<10^{23}$ \\
\hline Annual fluence & $10^{27}$ & $10^{29}$ & $10^{31}$ & $10^{25}$ & $10^{29}$ \\
\hline Good diagnostic access & $\mathrm{Y}$ & $\mathrm{Y}$ & $\mathrm{Y}$ & $\mathrm{N}$ & $\mathrm{N}$ \\
\hline Flexibility to target changes & $\mathrm{Y}$ & $\mathrm{Y}$ & $\mathrm{Y}$ & $\mathrm{N}$ & $\mathrm{N}$ \\
\hline $\begin{array}{l}\text { Surface morphology changes and } \\
\text { dynamics of dust (confinement) }\end{array}$ & $\mathrm{N}$ & $\mathrm{N}$ & Y & $\mathrm{N}$ & $\mathrm{Y}$ \\
\hline $\begin{array}{l}\text { Neutron-irradiated target } \\
\text { samples }\end{array}$ & $\mathrm{Y}$ & $\mathrm{N}$ & $\mathrm{N}$ & $\mathrm{N}$ & $\mathrm{N}$ \\
\hline $\begin{array}{l}\text { Test of divertor component } \\
\text { mock-ups }\end{array}$ & $\mathrm{N}$ & $\mathrm{N}$ & Y & $\mathrm{N}$ & Y \\
\hline
\end{tabular}

Within the United States, two linear facilities address many aspects of PMI science mentioned above. PISCES-B has already substantially contributed to the development of PMI science. Its strength is related to an extensive diagnostic array and its ability to systematically vary plasma parameters enabling PMI model validation. It is unique in that it can investigate mixed materials identical to the ITER material mix involving beryllium. It is, therefore, the primary test bed for the development of PMI science in support of the ITER design and the preparation of the ITER operation phase. TPE is a less powerful linear plasma device based on the same source concept as PISCES-B and is dedicated to fusion safety issues, such as invessel tritium source term and ex-vessel release source term assessments. It is unique in that it can expose materials to tritium plasmas and handle neutron-irradiated material; therefore, it serves as the primary test bed for investigating tritium behavior (e.g., retention and permeation) in neutron-irradiated PFCs in support of ITER D-T operation and future FNSF design. Because both the PISCES-B and TPE experimental setups use material test coupons, they contribute to the development of PFCs to a technical readiness level (TRL) of up to 3 as outlined by the 2012 FESAC report [4].

\subsection{LIMITATIONS OF EXISTING LINEAR DEVICES}

Although several linear plasma test stands are currently in operation in the United States and abroad, these devices are not capable of reaching the plasma parameter range needed to address all of the scientific issues identified above. In the following we list limitations and identify opportunities for improvements in future linear devices, which will enable new science and further the case towards fusion energy. 


\subsubsection{Biased Target Operation}

Most linear plasma devices, like the current US plasma devices (PISCES and TPE), bias their target to produce high fluxes [71] and hence do not have thermal plasmas in front of the target. As a result, these devices cannot reproduce the physics of sheath formation with an oblique magnetic field as will be present in a reactor divertor. The presence of a magnetic pre-sheath, in particular, determines prompt redeposition [72,73] and affects other PMI processes [74,75], indicating the need for a facility that can produce high-power-flux thermal plasmas without the need to bias the target. At small angles between the magnetic field and the surface, the sheath and pre-sheath will become more important. In a simplified view, the ions and electrons undergo a longer path through the sheath and pre-sheath. In the parameter range of future fusion reactors, ions sputtered from the surface will get ionized in the sheath and will then subsequently get accelerated toward the surface again [73]. This process is particularly important for tungsten ions, where a large fraction of the sputtered tungsten is redeposited in this way immediately. Furthermore, the ion energy of the redeposited tungsten is low, since the mean charge state the sputtered tungsten is ionized to is much lower in the case of oblique incidence sheath [73]. Secondary electron emission can lower the potential drop over the sheath [75], which would effectively reduce the ion energy of the impinging ions and change the erosion yield. However, if the surface is tilted with respect to the magnetic field to very shallow angles, electrons being reflected from the surface or being emitted as secondary electrons will be reabsorbed by the surface to a large fraction after only one gyro-motion. Five degrees seems to be sufficient to reabsorb almost all secondary electrons [75]. Otherwise, the ion energy distribution does not depend on the angle of the magnetic field at all, whereas the gyro-motion strongly affects the impact angle of the ion [75]. For shallow angles of 5 degrees, the angle of incidence of the ions is a distribution function with its maximum at about 20 degrees and a minimum of zero at 0 degrees and larger than 40 degrees. From the above-mentioned effects, one can conclude that a field-line angle of about 5 degrees is probably low enough to cover all the physics related to the secondary electron emission. Prompt redeposition of eroded ions will be affected in the same manner. Because the angle of incidence of ions coming toward the surface is on average substantially larger than the angle of the magnetic field to the target, an investigation of very shallow angles between the magnetic field and the target is not necessary. A reduction of the sputtering yield due to a reduced average kinetic energy of the impinging ions, if present, should be observable already at field-line angles of 10 or 20 degrees.

In addition, because of biasing, the ion energies are mostly above those expected at the strike point of a partially detached divertor, where electron temperatures are on the order of only $1-2 \mathrm{eV}$. As already described above, this can have a significant impact on the ion penetration into the bulk plasma, especially if the plasma fluxes are high as expected in a fusion reactor divertor plasma. Conclusions about the flux and fluence dependence on tritium retention, for example, can be very wrong.

\subsubsection{Limitation to Low Electron Temperature or Low Electron Density}

The current US plasma devices are not only limited to non-thermal plasmas with biased target; they also are restricted in the electron density range of operation. High electron densities like those expected in a fusion reactor divertor plasma of $10^{20} \mathrm{~m}^{-3}$ to $10^{21} \mathrm{~m}^{-3}$ cannot be reached. This has a direct impact on the local redeposition of the erosion products in front of the target. The mean-free path of the erosion products strongly depends on the electron density in front of target as well as the electron temperature gradient. Local redeposition cannot be investigated in those plasmas. This has a direct impact on the value of high-fluence plasmas. If the local redeposition physics is not representative of a fusion reactor, the evolving surfaces are expected to be very different. Although the most advanced linear test stand currently in operation worldwide (Magnum-PSI [76]) can reach the required ion and heat fluxes with a thermal plasma column, the electron and ion temperature range is limited below $5 \mathrm{eV}$. This limits the accessible regimes to the detached region of the divertor very near the strike point. For such low electron temperatures, the physical erosion-yield for the candidate plasma-facing material tungsten is so small that 
erosion is negligible from the steady-state power fluxes. As discussed above, the attached region away from the strike point, where $5<T_{\mathrm{e}}<15 \mathrm{eV}$, will be a net erosion zone and hence determine the PFC lifetime. This is because light impurities introduced to dissipate power in a divertor plasma create nonnegligible physical sputtering of tungsten. This means that Magnum-PSI cannot draw conclusions on the lifetime of a divertor because it cannot reach the respective high electron temperatures to ionize light impurities to higher ionization stages, and it cannot reach the target electron temperatures where physical sputtering due to light impurities will take place. In addition, Magnum-PSI is currently not able to operate at steady state with shallow magnetic field angles to the target (due to plasma source limitations).

\subsubsection{Limitations in Magnetic Fields}

Similar to the approach already introduced by Whyte et al. [77], the PMI figures of merit can be formulated in dimensionless quantities for scaling the magnetic pre-sheath effects and lateral dimension size of the system (plasma jet diameter). Important parameters for the definition of the system size are tabulated below. Here $\lambda_{T}$ is the poloidal scale length of the plasma close to the target (SOL width with flux expansion in divertor), which is equivalent to the width of the plasma jet of a linear plasma device. $L_{\text {mps }}$ is the magnetic pre-sheath length. Table 5 shows that for divertor plasmas with low electron temperatures $(<2 \mathrm{eV})$ and high plasma density ionization within the sheath is negligible. For the erosion products methane and tungsten, the mean-free path is longer than the magnetic pre-sheath length. Consequently the sheath region is transparent to the erosion products. For the high-power plasmas and at high electron temperatures of about $10 \mathrm{eV}$, a large fraction of tungsten impurities will be ionized within the sheath, and to some extent, this is also true for carbon (methane). However, tungsten has a large gyroradius (larger than ionization mean-free path [MFP]), and after ionization it will be redeposited promptly, having no time to experience any drifts in the pre-sheath. Some of the sheath physics can be addressed in experiments with reduced magnetic field and plasma density, which would relax demands on the maximum magnetic field. Hence, a match of the absolute magnetic field strength of future fusion reactors is not required. However, the confinement of nanometer-scale dust particles needs to be ensured. This requires a minimum magnetic field, depending on the collisionality of the dust particles with the background plasma [76]. For the lower-electron-temperature high-density plasma, the friction with the majority ions will be important for the transport of the erosion products (impurities) back to the surface. In the following equation, the flow velocity of impurity ions for a simple 1-D plasma fluid case [78] is shown:

$$
v_{z \|}=v_{i \|}+\frac{1}{m_{z} v_{i z}}\left(Z e E_{\|}-\frac{1}{n_{z}} \frac{d p_{z}}{d s}+0.71 Z^{2} \frac{d T_{e}}{d s}+2.6 Z^{2} \frac{d T_{i}}{d s}\right) .
$$

The first term in the parentheses of equation (1), $Z e E_{\|}$, is negligible for the regions outside the magnetic pre-sheath. The second term in parentheses is related to the diffusion of the impurities parallel to the magnetic field. This term is small in comparison to the two last terms, which constitute the thermal forces driving the impurities upstream in direction of the electron and ion temperature gradient. After those simplifications, one can write the impurity flow velocity driven by the friction with the flow of the majority ions $v_{i \|}$, which are directed toward the target and thermal forces that are directed away from the target:

$$
v_{z \|}=v_{i \|}+\frac{1}{m_{z} v_{i z}}\left(0.71 Z^{2} \frac{d T_{e}}{d s}+2.6 Z^{2} \frac{d T_{i}}{d s}\right)
$$

The friction force depends on the ion-impurity collision frequency $v_{i z}$ and hence linearly on plasma density $n_{e}$. We thus include the divertor collisionality as another dimensionless parameter in Table 5 . The thermal force is proportional to the temperature gradient and therefore the heat flux,so it may be possible 
to reduce the density and heat flux simultaneously compared to a reactor and still achieve the relevant impurity transport regime.

Table 5. Dimensionless parameters for PMI. The electron impact ionization mean-free path is $\lambda_{\mathrm{e}} ; \lambda_{\mathrm{CX}}$ is the meanfree path for charge exchange processes; $\lambda_{\mathrm{CH} 4}$ is the electron impact ionization mean-free path of methane; $\lambda_{\mathrm{W}}$ is the electron impact ionization mean-free path of tungsten; $\rho_{\mathrm{w}}$ is the Larmor radius of single ionized tungsten; $\nu^{*}$ DIV is

the divertor collisionality; and $\lambda_{\mathrm{mps}}$ is the length of the magnetic pre-sheath.

\begin{tabular}{|c|c|c|c|c|c|c|}
\hline $\begin{array}{l}\text { Normalized } \\
\text { parameters } \\
\text { description }\end{array}$ & $\begin{array}{c}\text { Dimensionless } \\
\text { quantity }\end{array}$ & $\begin{array}{c}\text { General } \\
\text { scaling }\end{array}$ & $\begin{array}{l}\text { ITER Outer } \\
\text { Strike Point }\end{array}$ & $\begin{array}{c}\text { ITER high } \\
n_{e}\end{array}$ & $\begin{array}{l}\text { ITER } \\
\text { high P }\end{array}$ & $\begin{array}{c}\text { ITER } \\
\text { high Te }\end{array}$ \\
\hline D ionization MFP & $\lambda_{e i} / \lambda_{T}$ & $\sim n_{e}^{-1} T_{e}^{-3 / 2}$ & 0.54 & 1.3 & 0.4 & 0.56 \\
\hline $\begin{array}{l}\text { D diffusive neutral } \\
\text { MFP }\end{array}$ & $\lambda_{C X} / \lambda_{T}$ & $\sim n_{e^{-2}}$ & 0.9 & 0.18 & 0.24 & 0.4 \\
\hline $\mathrm{W}$ gyroradius & $\rho_{W} / \lambda_{T}$ & $\sim B^{-1} T_{e}^{1 / 2}$ & 0.01 & 0.01 & 0.05 & 0.06 \\
\hline $\begin{array}{l}\mathrm{CH}_{4} \text { ionization } \\
\text { MFP }\end{array}$ & $\lambda_{\mathrm{CH} 4} / \lambda_{T}$ & $\sim n_{e}^{-1} T_{e}^{-(\alpha+1 / 2)}$ & Transparent $^{1}$ & 470 & 0.02 & 0.02 \\
\hline D ionization MFP & $\lambda_{e i} / L_{m p s}$ & $\sim B n_{e}^{-1} T_{e}^{-2}$ & 7450 & 684 & 31 & 37 \\
\hline $\mathrm{CH}_{4} \mathrm{MFP}^{2}$ & $\lambda_{\mathrm{CH} 4} / L_{m p s}$ & $\sim B n_{e}^{-1} T_{e}^{-\alpha}$ & Transparent $^{1}$ & Transparent $^{1}$ & 1.6 & 1.5 \\
\hline $\mathrm{W}$ ionization $\mathrm{MFP}^{3}$ & $\lambda_{W} / L_{m p s}$ & $\sim B n_{e}^{-1} T_{e}^{-\beta}$ & $1 \mathrm{E}+5$ & 91 & 0.16 & 0.26 \\
\hline $\begin{array}{l}\text { W gyroradius / W } \\
\text { ionization MFP }\end{array}$ & $\rho_{W} / \lambda_{W}$ & $\sim B^{-1} n_{e} T_{e}^{-(\beta-1 / 2)}$ & $1 \mathrm{E}-5$ & 0.05 & 25 & 15 \\
\hline $\begin{array}{l}\text { Divertor } \\
\text { collisionality }\end{array}$ & $v *_{D I V}$ & $\sim n_{e} T_{e}^{-2} L_{D I V}$ & $10^{7}-10^{8}$ & Same & Same & Same \\
\hline
\end{tabular}

In addition, a strong magnetic field is required to study the effect of ELM-like transients on melt-layer movements. Strong transient heat fluxes from ELMs might melt the surface of metal PFCs. Plasma guns (e.g., QSPA) studied the effect of transient plasma fluxes on the melt-layer movement. Such devices do not have a strong magnetic field. Hence any $\mathbf{j} \times \mathbf{B}$ forces acting on the melt-layer movement cannot be investigated. The same is true to for the US plasma devices (e.g., PISCES, TPE), which are equipped with lasers to simulate transient events. Melt-layer movement cannot be simulated appropriately because the magnetic fields are too low. The current US plasma devices have magnetic fields of $0.2 \mathrm{~T}$ or less. This is a factor of 20-30 below the magnetic fields in a fusion reactor.

\subsubsection{Ability to Study Conduction Limited Transport}

Most linear plasma devices use an electrostatic discharge, mostly coaxial arrangement of electrode and anode. Those plasma sources provide a convective transport of energy and particles to the target.

\subsubsection{Ability to Study Neutron-Irradiated Materials}

Most linear devices are not designed to address the PMI of neutron-irradiated materials with the exception of TPE. Therefore, many experiments are based on high-energy ion-irradiated material samples. This has the advantage that materials can be irradiated with other impurities to very high dpa very quickly, but it also has the disadvantage that bulk damage and its consequences cannot be assessed. Furthermore, the rate of the displacement damage is too fast when compared to neutron-induced displacement damage. Annihilation of cascade damages happens at a constant rate. To simulate the low neutron irradiation rate, 
high-energy ion irradiation needs to be carried out at the higher temperatures to increase the rate of annihilation of cascade damages.

An issue common to all of the existing devices is the use of internal electrodes that can emit unwanted impurities, complicating the plasma-surface interaction processes and their interpretation drastically. This is particularly important for low-temperature, high-density, high-fluence exposures, where small amounts of medium- to high- $\mathrm{Z}$ impurities originating from electrodes will accumulate on the target. 



\section{NEED FOR UPGRADED OR NEW CAPABILITIES TO ADDRESS PMI SCIENCE GAPS}

A recent community poll at the Fusion Energy Science Workshop on Plasma Material Interactions identified the following PMI research areas as being important:

- Material erosion, migration, mixed materials, and deposits

- Tritium retention, migration, and codeposition

- Surface and material evolution (morphology) due to H, He, N, and others

- Change of PMI at high fluence (erosion, thermodynamics, dust, etc.) and end-of-life tests

- Neutron effects

- Material response to transients

- PMI of novel PFCs (liquid metal, high-temperature PFCs, etc.)

The high-priority research areas, suggested contributions from short pulse and long pulse tokamaks and existing linear devices, and associated research needs are listed in Table 6. Those research needs are also reflected in the report of the Fusion Energy Sciences Plasma Material Interactions Workshop. During the workshop, the community recommended two new issues to address: (1) long pulse PMI science and (2) power exhaust challenges for future fusion reactors. With both new builds, the PFC TRL can be increased from today's level of 3 to a level of 6 in many aspects. Achieving a TRL level of $7-9$ would require the FNSF and DEMO device, both multibillion dollar facilities [4].

Table 6. PMI research areas and current contributions from tokamaks and linear devices to this research as well as research needs in the future.

\begin{tabular}{|c|c|c|c|c|}
\hline $\begin{array}{l}\text { Research } \\
\text { areas }\end{array}$ & $\begin{array}{c}\text { Short pulse } \\
\text { tokamaks }\end{array}$ & $\begin{array}{l}\text { Long pulse } \\
\text { tokamaks }\end{array}$ & $\begin{array}{c}\text { Existing linear } \\
\text { devices }\end{array}$ & Research needs \\
\hline $\begin{array}{l}\text { Material erosion, } \\
\text { redeposition, } \\
\text { migration, mixed } \\
\text { materials, and } \\
\text { deposits }\end{array}$ & $\begin{array}{l}\text { Erosion, } \\
\text { redeposition, and } \\
\text { migration }\end{array}$ & $\begin{array}{l}\text { Migration, } \\
\text { deposits, dust } \\
\text { production }\end{array}$ & $\begin{array}{l}\text { Erosion, mixed } \\
\text { materials, Be }\end{array}$ & $\begin{array}{l}\text { Erosion, redeposition, } \\
\text { migration, mixed } \\
\text { materials, with } \\
\text { improved diagnostics }\end{array}$ \\
\hline $\begin{array}{l}\text { Hydrogen }(\mathrm{T}) \\
\text { retention, migration, } \\
\text { and codeposition }\end{array}$ & $\begin{array}{l}\text { Mostly T retention } \\
\text { due to codeposition, } \\
\text { ex situ analysis of } \mathrm{T} \\
\text { retention in bulk }\end{array}$ & $\begin{array}{l}\mathrm{T} \text { codeposition, } \\
\text { ex situ analysis of } \\
\mathrm{T} \text { retention in bulk }\end{array}$ & $\begin{array}{l}\text { T-retention, } \\
\text { permeation, and } \\
\text { codeposition }\end{array}$ & $\begin{array}{l}\text { T-retention, permeation } \\
\text { at high temperature, and } \\
\text { radiation-damaged } \\
\text { materials }\end{array}$ \\
\hline $\begin{array}{l}\text { Surface and material } \\
\text { evolution } \\
\text { (morphology) due to } \\
\mathrm{H}, \mathrm{He}, \mathrm{Be}, \mathrm{N} \text {, and } \\
\text { other seeded gases }\end{array}$ & $\begin{array}{l}\text { Some work on } \\
\text { DIMES, MAPP etc. }\end{array}$ & Not addressed yet & $\begin{array}{l}\text { Morphology } \\
\text { changes } \\
\text { investigated } \\
\text { extensively }\end{array}$ & $\begin{array}{l}\text { Improved material } \\
\text { evolution } \\
\text { characterization with } \\
\text { enhanced diagnostic } \\
\text { capabilities }\end{array}$ \\
\hline $\begin{array}{l}\text { Change of PMI at } \\
\text { high fluence } \\
\text { (erosion, } \\
\text { redeposition, } \\
\text { thermodynamics, } \\
\text { dust, etc.) and end- } \\
\text { of-life tests }\end{array}$ & $\begin{array}{l}\text { Dust dynamics, dust } \\
\text { inventory campaign } \\
\text { averaged, dust due } \\
\text { to melt-layer } \\
\text { splashes }\end{array}$ & $\begin{array}{l}\text { Dust production } \\
\text { after high fluence, } \\
\text { dust dynamics }\end{array}$ & $\begin{array}{l}\text { Fluence of } \\
10^{28} \mathrm{~m}^{-2} \text { reached }\end{array}$ & $\begin{array}{l}\text { Fluence significantly } \\
\text { beyond } 10^{28} \mathrm{~m}^{-2}\end{array}$ \\
\hline $\begin{array}{l}\text { Neutron effects on } \\
\text { PMI }\end{array}$ & $\mathrm{N} / \mathrm{A}$ & $\mathrm{N} / \mathrm{A}$ & $\begin{array}{l}\text { Some work on } \\
\text { TPE }\end{array}$ & High dpa, high $\mathrm{He} / \mathrm{dpa}$ \\
\hline
\end{tabular}


Table 6. PMI research areas and current contributions from tokamaks and linear devices to this research as well as research needs in the future (continued).

\begin{tabular}{|l|l|l|l|l|}
\hline & \multicolumn{1}{|c|}{$\begin{array}{c}\text { Short pulse } \\
\text { tokamaks }\end{array}$} & \multicolumn{1}{|c|}{$\begin{array}{c}\text { Long pulse } \\
\text { tokamaks }\end{array}$} & $\begin{array}{c}\text { Existing linear } \\
\text { devices }\end{array}$ & \multicolumn{1}{c|}{ Research needs } \\
\hline $\begin{array}{l}\text { Material response to } \\
\text { transients (ELMs) }\end{array}$ & $\begin{array}{l}\text { C ablation, W } \\
\text { melting at JET }\end{array}$ & $\begin{array}{l}\text { ELMs too small } \\
\text { by pulsed arc, } \\
\text { laser, ELM } \\
\text { threshold damage }\end{array}$ & $\begin{array}{l}\text { ELM simulation closer } \\
\text { to tokamak conditions: } \\
\text { conv./ ExB / } \mathrm{E}_{\mathrm{i}}\end{array}$ \\
\hline $\begin{array}{l}\text { PMI of novel PFCs } \\
\text { (e.g., liquid metals) }\end{array}$ & $\begin{array}{l}\text { Li as wall } \\
\text { conditioning applied }\end{array}$ & $\begin{array}{l}\text { Li as wall } \\
\text { conditioning } \\
\text { applied }\end{array}$ & $\begin{array}{l}\text { Li-coated sample } \\
\text { tests, liquid Li } \\
\text { target tests }\end{array}$ & $\begin{array}{l}\text { Concept validation of } \\
\text { flowing Li target }\end{array}$ \\
\hline
\end{tabular}

In summary, there is a need for linear devices, short pulse toroidal devices, and long pulse toroidal devices in which to carry out an integrated PMI R\&D program:

- Existing linear devices for single to few effects studies and benchmarking of PMI computational models.

- A new linear device for integration of many effects (flux, fluence, neutrons, $T$, near surface transport) to advance PFC development to TRL 6.

- Short pulse tokamaks to study the effect of impurities (candidate materials) on confinement scenarios and material migration in toroidal geometry.

- Long pulse tokamaks to develop steady-state scenarios compatible with plasma plasma-facing materials with respect to confinement, erosion/redeposition (dust production), $T$-retention.

- A new Divertor Tokamak Test (DTT) facility for investigation of power exhaust at high parallel heat fluxes with advanced divertors [8].

A DTT will be a major device with an investment of several $\$ 100 \mathrm{M}$ [8]. Several options are possible here- either a small tokamak with a high magnetic field to obtain high heat fluxes to test different divertor geometries, albeit at the risk that the results cannot be extrapolated to a larger reactor due to limitations in divertor identity at high density and questionable operation regimes, or alternatively an upgrade of a medium-sized tokamak with a different novel divertor geometry, which will be easier to extrapolate to a larger tokamak but might not be that flexible to geometry changes.

For the development of new materials for PFCs, the use of a steady-state linear devices is not avoidable. The limitations of the current devices have been listed above. A new device needs to do the following:

- extend the ion fluxes significantly above $10^{23} \mathrm{~m}^{-2} \mathrm{~s}^{-1} \rightarrow$ possible sources: high-pressure arc, helicon plasma source

- be able to operate in steady state with magnetic fields of $>1 \mathrm{~T} \rightarrow$ superconducting magnets

- be able to deliver parallel heat fluxes of $40 \mathrm{MW} / \mathrm{m}^{2} \rightarrow$ high-pressure arc or RF-heated plasma

- be able to operate in steady state with targets at an oblique angle of 5 degrees $\rightarrow$ thermal plasma, no axial currents 
- reach plasma parameters in front of target of $n_{\mathrm{e}}=10^{21} \mathrm{~m}^{-3}$ and $T_{\mathrm{e}}=15 \mathrm{eV}$ (not simultaneously) $\rightarrow$ electron and ion heating of plasma, likely with RF; alternative approach would be gas dynamic trap

- have a whole source system able to operate in steady-state $\rightarrow$ gas dynamic trap has not demonstrated steady-state operation, nor another mirror device like GAMMA10

- have a source system that does not lead to impurity production, which could spoil the PMI experiment $\rightarrow$ RF- produced and heated plasma

- be able to introduce a priori neutron-irradiated materials

- have an extensive in situ and in-vacuo diagnostic set

- be available for PMI studies for other users 



\section{THE PROPOSED MATERIAL PLASMA EXPOSURE EXPERIMENT (MPEX)}

To address the PMI science above, a new device is needed with increased capabilities. The proposed Material Plasma Exposure eXperiment will address critical fusion nuclear science on the road to a viable reactor. MPEX would extend the parameter range accessible in present worldwide capabilities using a cost-effective, linear configuration conducive to thorough diagnosis and rapid testing.

MPEX would be a direct response to the FESAC report on Opportunities for Fusion Materials Science and Technology Research Now and During the ITER Era with its overarching recommendation:

"Numerous fusion nuclear science feasibility issues can be effectively investigated during the next 5 to 10 years by efficient use of medium-scale facilities" [4]. The facility MPEX aims to fulfill the specifications given in ReNeW (Thrust 10), namely, ion fluxes of $\Gamma>10^{23} \mathrm{~m}^{-2} \mathrm{~s}^{-1}$, parallel power fluxes of $\sim 20 \mathrm{MW} / \mathrm{m}^{2}$, inclined target, $B>1 \mathrm{~T}$, steady state (up to $10^{6} \mathrm{sec}$ ), $>600^{\circ} \mathrm{C}$ surface temperature, large plasma area $\sim 100 \mathrm{~cm}^{2}$, including exposure of liquid-metal targets $\mathrm{Ga}, \mathrm{Sn}, \mathrm{Li}$, neutron-irradiated material samples with significant dpa, and independent control of $T_{e}$ and $T_{i}$ at target. Of the 15 major gaps in the Greenwald report [1], six (G7, G9, G10, G11, G12, G13) can possibly be addressed with MPEX. MPEX is geared to address all three key grand challenges (1-3) as outlined in the FESAC report by Zinkle et al..

As proposed, MPEX would be the only device worldwide to perform accelerated lifetime tests of tungsten divertors (Figures 2 and 3). It would be able to expose material samples and mock-up-sized PFC to fusion-reactor-relevant plasmas. It will be designed to test a large variety of candidate PFC materials (solid, liquid, carbon based, metallic, irradiated) under different experimental conditions (temperature, wall loading, etc.).

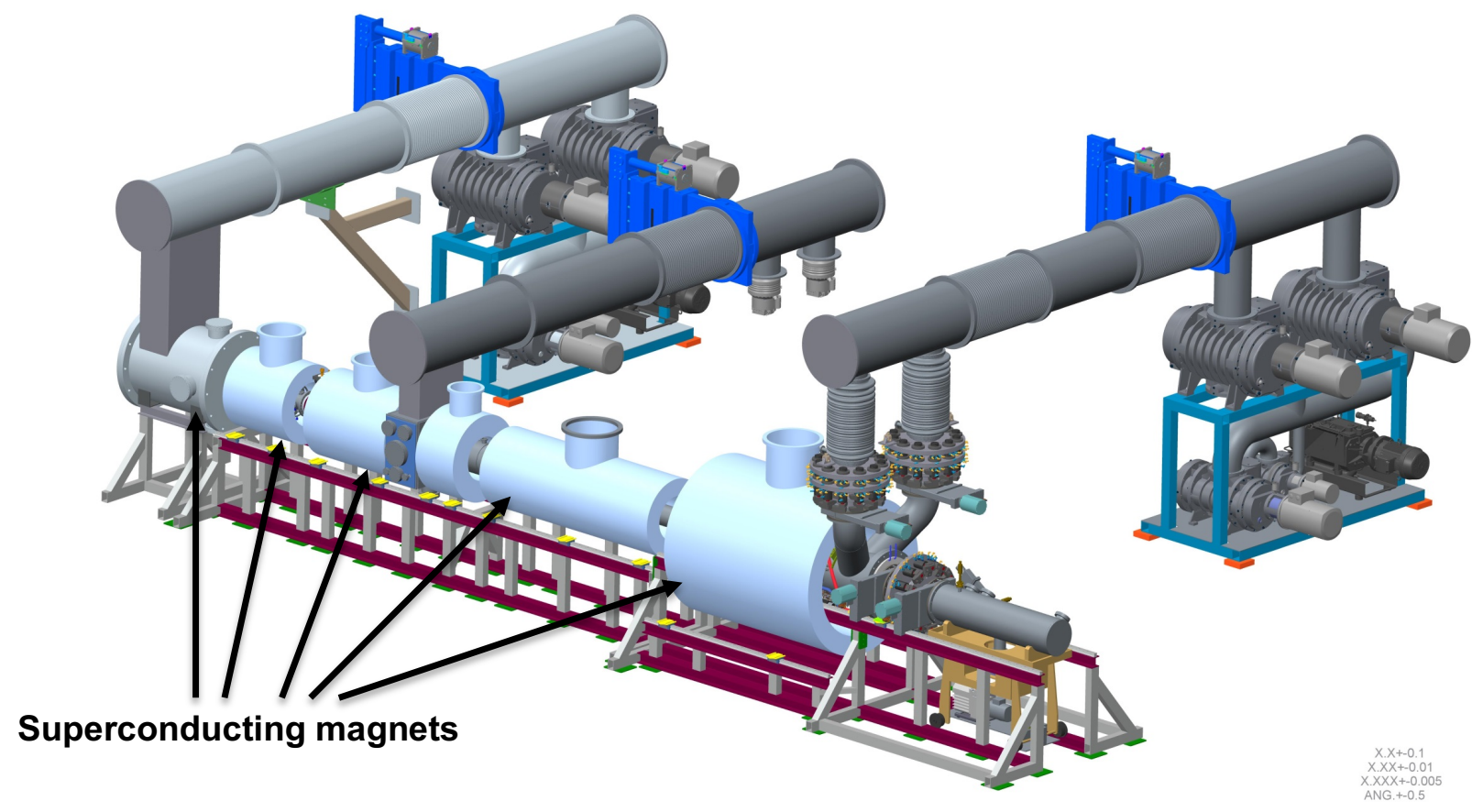

Figure 2. MPEX pre-design. 


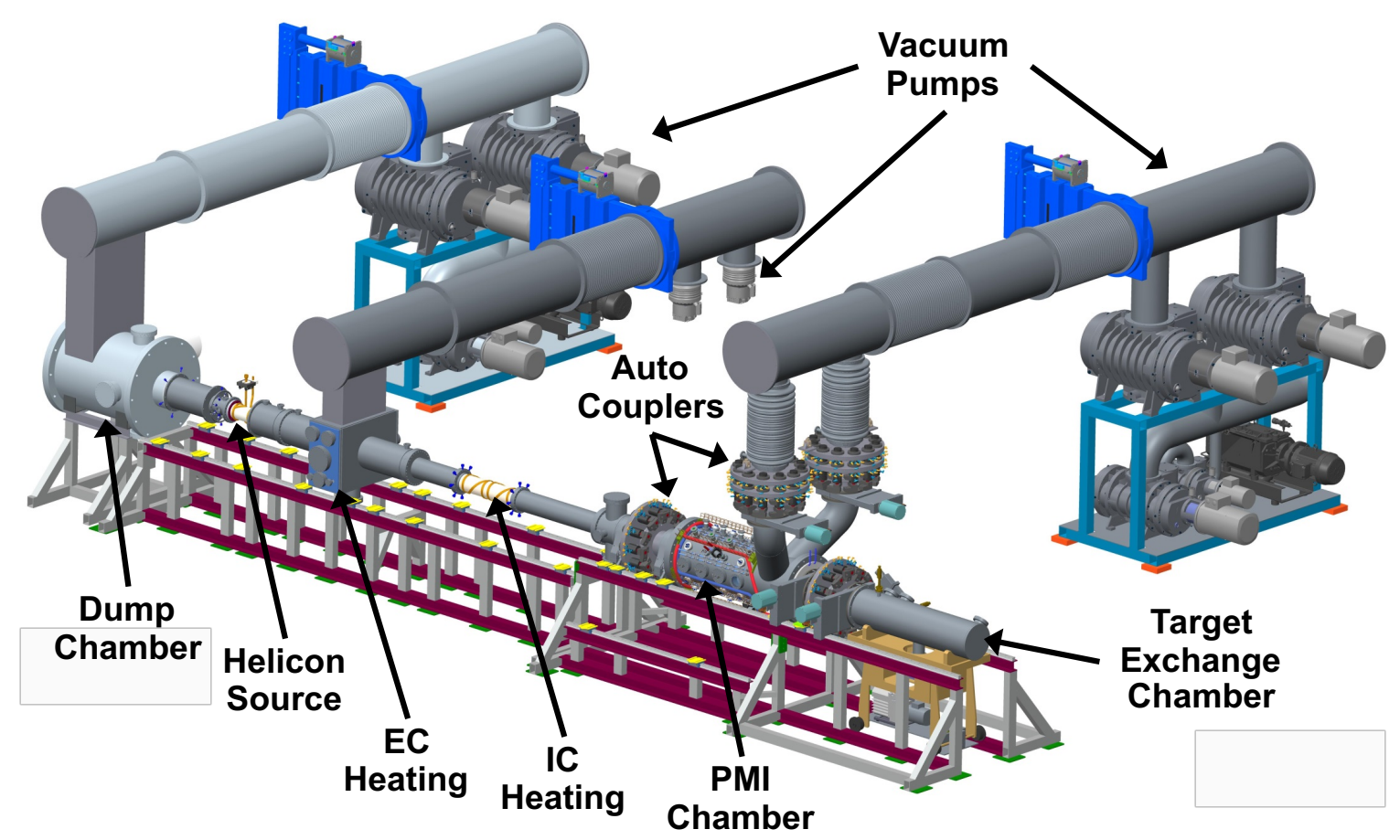

Figure 3. Pre-design of MPEX without magnets.

MPEX will be a steady-state device using superconducting coils with standard technology (NbTi). The plasma source for MPEX will be based on RF technology [9]. Plasma production will be facilitated by power coupled through a helicon wave antenna at a frequency in the range of 10-20 MHz. The helicon antenna has the advantage that the emitted circular polarized electromagnetic waves can propagate in the plasma at much higher densities than other waves. In MPEX, this helicon-produced source plasma will be heated in the electron cyclotron resonance frequency range $(\mathrm{ECH})$ and in the ion cyclotron resonance frequency range $(\mathrm{ICH})$ to increase the electron and ion temperature as well as the total heating power density. Two heating schemes in the electron cyclotron range that allow power coupling to the core plasma despite overdense $\left(\omega_{p e}>\omega_{c e}\right)$ conditions are being tested: (a) whistler wave electron cyclotron heating, which propagates in the plasma from the high-magnetic-field side to the resonance-magneticfield region and (b) electron Bernstein waves (EBW), which propagate in the plasma from the lowmagnetic-field side to the resonance-magnetic-field region. The total RF heating power will be up to $800 \mathrm{~kW}(200 \mathrm{~kW}$ helicon, $20 \mathrm{~kW} \mathrm{ECH}$, and $400 \mathrm{~kW} \mathrm{ICH})$. The magnetic field structure will be adopted to maximize the source and heating performance.

In addition to the advantages over toroidal devices, the approach used by MPEX has several advantages over other linear plasma wall interaction simulators:

1. The RF source system will minimize the production of intrinsic impurities, which is an advantage over linear plasma devices with internal electrodes in the source system. This will minimize impurity sources other than from the target in the linear device. It will also allow low maintenance operation, as required for steady-state operation.

2. The heat flux to the target, as well as the plasma parameters in front of the target, will be determined by the conduction limited transport parallel to the magnetic field, just like in a SOL of a toroidal device. This will permit the investigation of power load dissipation processes by impurity radiation, as well as permit the ionization of impurities to higher charge states that are important for physical 
sputtering studies of tungsten. This is not possible in other linear devices, where energy transport is often convection driven.

3. A high-power thermal plasma in front of the target allows the investigations of PMI in realistic geometric environments (target at oblique angle to magnetic field) with realistic $\mathrm{E}$ and $\mathrm{B}$ fields in the sheath. This is different from other linear plasma devices that either must make use of electrostatic biasing to reach significant heat and particle fluxes on the target or are influenced by instabilities driven by internal currents between the electrodes.

4. The MPEX heating systems will allow the electron temperature and ion temperature to be varied independently, allowing for sheath physics investigations other linear devices are not able to pursue.

5. MPEX will be designed to accept targets that have been irradiated by neutrons a priori to very high dpa levels. Not many linear devices are able to do this, and those that can handle activated materials to some level have a much-reduced experimental capability and are unable to address the scientific needs laid out in Sections 1-3.

The target station would be designed to allow for testing of novel target concepts. Versatile target casks would allow, for example, the exposure of hot targets (e.g., helium-cooled), flowing liquid metal targets, cascading pebble targets, and neutron-irradiated targets, among others.

MPEX will help to advance PFCs from concept exploration studies (TRL 3) to proof-of-principle solutions (TRL 4 up to TRL 6 for some end-of-lifetime studies). Building MPEX would provide the United States the opportunity for world leadership in the area of PMI. In particular, compared to Magnum-PSI, the current world-leading linear plasma device, MPEX would be able to study end-of-life tests of high- $Z$ material targets under reactor prototypic conditions. The low $T_{e}$ and $T_{i}$ in Magnum-PSI does not allow the investigation of erosion and redeposition processes due to physical and chemical erosion. Magnum-PSI is also unable to test neutron-irradiated material samples. Hence, the influence of the neutron irradiation on the lifetime of the plasma-facing materials and components cannot be tested in Magnum-PSI. Without MPEX or a facility with reduced specifications with respect to the ones mentioned in $\mathrm{ReNeW}$, the United States risks losing its leadership status.

MPEX's source concept is being tested at ORNL using Proto-MPEX. Proto-MPEX is a linear device utilizing 12 water-cooled copper coils from the former EBT experiment [79], which are able to deliver peak magnetic fields of up to $1.0 \mathrm{~T}$ in steady-state in a single coil arrangement and higher in combination with others. It is designed to test a $100 \mathrm{~kW}$ helicon plasma source, electron heating with a $200 \mathrm{~kW}$ $28 \mathrm{GHz}$ gyrotron and ion heating in the range of $6-12 \mathrm{MHz}$ with a $30 \mathrm{~kW}$ frequency tunable RF transmitter. A recent review [80] provides an overview of the development for MPEX. In Table 7 a comparison of the achieved performance against the target value is shown. Note, not all performance values have been achieved simultaneously, but all concepts for plasma production and heating have been validated. High densities were achieved with the helicon source. Significant electron heating in overdense plasmas was obtained [81], and ion heating was observed [82]. 
Table 7. Plasma parameters achieved on Proto-MPEX (as of December 2017) compared with the target performance values. Not all plasma parameters were achieved simultaneously.

\begin{tabular}{|l|l|l|l|}
\hline \multicolumn{1}{|c|}{ Parameter } & \multicolumn{1}{c|}{ Aimed value } & \multicolumn{1}{c|}{ Achieved value } & \multicolumn{1}{c|}{ Comments } \\
\hline$n_{\mathrm{e}}$ source & $4-6 \times 10^{19} \mathrm{~m}^{-3}$ & $8 \times 10^{19} \mathrm{~m}^{-3}$ & \\
\hline $\mathrm{n}_{\mathrm{e}}$ target & Up to $10^{21} \mathrm{~m}^{-3}$ & $1.1 \times 10^{20} \mathrm{~m}^{-3}$ & $2 \mathrm{~cm}$ in front of target \\
\hline $\mathrm{T}_{\mathrm{e} \text { source }}$ & Up to $25 \mathrm{eV}$ & $21 \mathrm{eV}$ & In overdense plasmas \\
\hline $\mathrm{T}_{\mathrm{e}}$ target & Up to to $15 \mathrm{eV}$ & $8 \mathrm{eV}$ & \\
\hline $\mathrm{T}_{\mathrm{i} \text { source }}$ & Up to $25 \mathrm{eV}$ & $16 \mathrm{eV}$ & Measured on Ar-II \\
\hline$T_{\mathrm{i} \text { target }}$ & Up to $20 \mathrm{eV}$ & & Not measured yet \\
\hline B target & $1-2 \mathrm{~T}$ & $1 \mathrm{~T}$ & Best results with $3 \mathrm{~cm}$ \\
\hline Plasma diameter & Up to $10 \mathrm{~cm}$ & $6 \mathrm{~cm}$ & At target \\
\hline$\Gamma_{\mathrm{I}}$ target & $>10^{24} \mathrm{~m}^{-2} \mathrm{~s}^{-1}$ & $>5 \times 10^{23} \mathrm{~m}^{-2} \mathrm{~s}^{-1}$ & \\
\hline $\begin{array}{l}\text { Min. angle of B to } \\
\text { target }\end{array}$ & 5 degrees & $90 \mathrm{degrees}$ & $\begin{array}{l}\text { In low } \mathrm{n}_{\mathrm{e}} \text { regime } \\
\text { In high } \mathrm{n}_{\mathrm{e}} \text { regime }\end{array}$ \\
\hline $\begin{array}{l}\text { P target, parallel } \\
\text { Up to } 40 \mathrm{MW} / \mathrm{m}^{2}\end{array}$ & $\begin{array}{l}>14 \mathrm{MW} / \mathrm{m}^{2} \\
>3 \mathrm{MW} / \mathrm{m}^{2}\end{array}$ & $\begin{array}{l}\text { In low } \mathrm{n}_{\mathrm{e}} \text { regime } \\
\text { In high } \mathrm{n}_{\mathrm{e}} \text { regime }\end{array}$ \\
\hline $\begin{array}{l}\text { P target, } \\
\text { perpendicular }\end{array}$ & $10 \mathrm{MW} / \mathrm{m}^{2}$ & $>14 \mathrm{MW} / \mathrm{m}^{2}$ \\
\hline
\end{tabular}

The construction of MPEX at ORNL will benefit from the laboratory's infrastructure for nuclear systems and from the proximity of the neutron irradiation sources nearby, namely, the High Flux Isotope Reactor and Spallation Neutron Source. MPEX would leverage not only ORNL's large-scale material irradiation facilities, but it would also leverage the infrastructure to handle and diagnose neutron-irradiated material samples of significant displacement damage. In principle, samples can be irradiated at those facilities and sent to other plasma devices for exposures (e.g., TPE, as done for some cases within the PHENIX program). However, shipping of more highly activated samples is easier within the ORNL site than shipping to the Idaho National Laboratory (INL). Also, a complete front-to-end design of the material flow from irradiation capsule design for the High Flux Isotope Reactor to the sample holder in MPEX and subsequent characterization with high-resolution scanning electron microscopy/transmission electron microscopy is easier and straightforward. Complementing MPEX with in-situ and in-vacuo diagnostics will be essential for the characterization of the material evolution during its plasma exposure process up to end-of-life. Documentation of failure modes of PFCs is only one part of the process. Much more important is developing a diagnostic set that will allow for high time- and space-resolved data.

ORNL features a unique combination of expertise in material science, surface science, manufacturing processes, PMI science, and computational capabilities that can accelerate the development of this technology and produce innovative solutions. ORNL has a strong foundation in developing material diagnostics that can provide insight into the science of radiation-damaged materials. This expertise will be indispensable in the design of MPEX and its operation, as well as during the scientific exploitation itself. ORNL's portfolio of interdisciplinary expertise and its world-class facilities will ensure the best return on investment for MPEX. Advanced manufacturing techniques, such as additive manufacturing also have the potential to lead to transformational solutions for the novel PFCs that MPEX will be used to test. ORNL also has a strong cadre of experts in this area. With ORNL's Manufacturing Demonstration Facility, the Department of Energy's first of this kind, new solutions for PFCs can be quickly developed and tested. Analysis, synthesis, empirical scaling, and experimental approaches are used to develop new materials. 
The ever-growing resolution of diagnostics allows a level of analysis that can be used most appropriately for benchmarking computational models of materials and components. From ab-initio calculations to selfconsistent solutions of an integrated plasma-material interface with structural viable PFCs, computational approaches that go beyond the current approaches are necessary. Novel algorithms are expected to make use of the full breadth of the leadership computational facilities at ORNL and will complement the experimental approach to new PFC solutions, eventually leading to a predictive capability for plasmamaterial interactions. Most likely these predictive capabilities will be built upon data from a new device like MPEX, which can explore unchartered territory for fusion plasma-facing materials. It is the vision that an emerging predictive capability and mature advanced manufacturing methods will lead to a design of plasma-facing components within a time frame of 15 years, which is incomprehensible at this moment. This would be timely for the deployment of the next step fusion facility on the horizon.

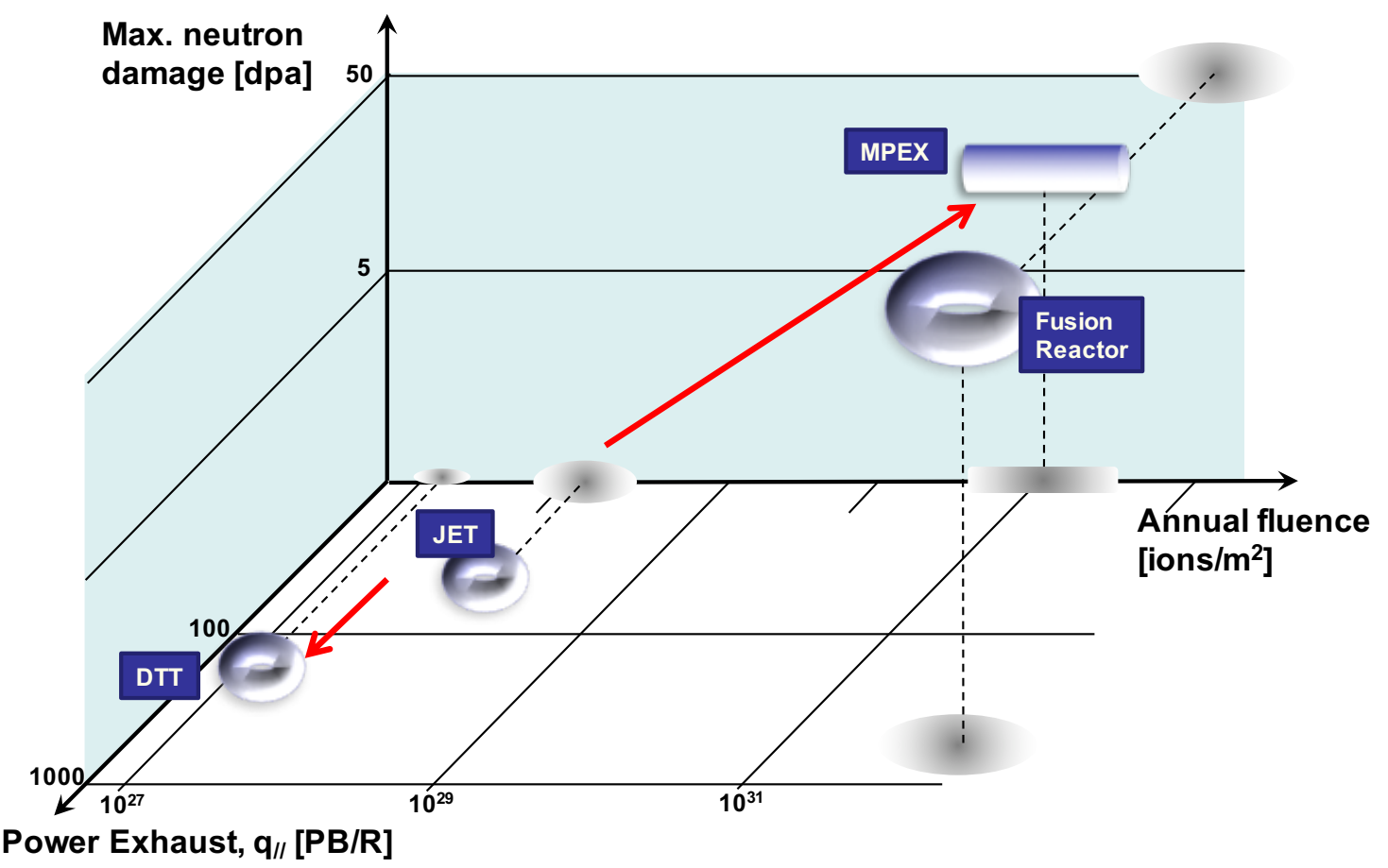

Figure 4. Contribution of MPEX to finding solutions for the development of plasma-facing components with addressing plasma material interactions at high fluence with materials, which have a priori exposure to high neutron fluence.

The estimated cost range for MPEX is $\$ 30 \mathrm{M}-\$ 42 \mathrm{M}$. The duration of this project is anticipated to be 5.5 years from initial project approval without financial constraints. Starting this project now will allow MPEX to contribute to the design of the second divertor in ITER. It would also ensure that plasma-facing materials for a FNSF would be tested in time for such a device to be built. This should be compared to a divertor tokamak test facility, which most likely will be in the several $\$ 100 \mathrm{M}$ cost range. 



\section{REFERENCES}

[1] Greenwald Panel Fusion Energy Sciences Advisory Committee Report, October 2007, https://science.energy.gov/ /media/fes/fesac/pdf/2007/Fesac_planning_report.pdf.

[2] Research Needs for Magnetic Fusion Energy Sciences - Report of the Research Needs Workshop (ReNeW), 2009, https://science.energy.gov/ /media/fes/pdf/workshopreports/Res_needs_mag_fusion_report_june_2009.pdf.

[3] "R\&D Needs and Required Facilities for the Development of Fusion as an Energy Source," European Communities, 2008, http://ec.europa.eu/research/energy/pdf/978-92-79-100574_en.pdf.

[4] Department of Energy. Opportunities for Fusion Materials Science and Technology Research Now and During the ITER Era. Report No. DOE/SC-0149, http://science.energy.gov/ /media/fes/pdf/workshop-reports/20120309/FESAC-MaterialsScience-final-report.pdf.

[5] Report of the FESAC Subcommittee on the Priorities of the Magnetic Fusion Energy Science Program, http://science.energy.gov/ /media/fes/fesac/pdf/2013/Final-Report02102013.pdf.

[6] Fusion Energy Sciences Advisory Committee, Report on Strategic Planning, Priorities Assessment and Budget Scenarios, October 10, 2014, https://science.energy.gov/ /media/fes/fesac/pdf/2014/October/FESAC_strategic_planning _rept_dec14.pdf.

[7] E. Synakowski, Fusion Energy Sciences Advisory Committee Public Meeting, January 13, 2016, https://science.energy.gov/ /media/fes/pdf/program-documents/FES_A_TenYear_Perspective_2015-2025.pdf.

[8] Report of Plasma Materials Interactions Workshop (Princeton, NJ, USA, May 4-7, 2016), https://science.energy.gov/ /media/fes/pdf/workshopreports/2016/PMI_fullreport_21Aug2015.pdf.

[9] R. A. Pitts et al., J. Nucl. Mater. (2011).

[10] M. Rieth et al. "International Tungsten Development Efforts and the Gas Cooled Divertor Design" International Conference on Fusion Reactor Materials-15 (Charleston, SC, USA, October 16-22, 2011).

[11] M. Rieth et al., J. Nucl. Mater. 417 (2013) 463.

[12] T. Eich et al., Phys. Rev. Lett. 107215001 (2011).

[13] D. Maisonnier et al., Fus. Eng. Des. 811123 (2006).

[14] C. Kessel et al., Fus. Sci. Technol. 67 (2015) 1.

[15] M. Shimada et al., J. Plasma Fusion Res. Ser. 377 (2000).

[16] J. Rapp et al., Nucl. Fusion 49095012 (2009).

[17] A. Kallenbach et al., Nucl. Fusion 52122003 (2012).

[18] J. Rapp et al., EU DEMO workshop (2011).

[19] A. Kallenbach et al., Nucl. Fusion 49045007 (2009).

[20] J. Rapp et al., Nucl. Fusion 52122002 (2012). 
[21] M. Wischmeier et al., 24th IAEA Fusion Energy Conference (St. Petersburg, Russia, October 13-18, 2014).

[22] A. Huber et al., 41 st EPS Conference on Plasma Physics (Berlin, Germany, June 23-27, 2014).

[23] M. Kotschenreuther et al., Phys. Plasmas 20102507 (2013).

[24] M. Kotschenreuther et al., Phys. Plasmas 14072502 (2007).

[25] P.M. Valanju et al., Phys. Plasmas 16056110 (2009).

[26] B. LaBombard et al., Nucl. Fusion 55053020 (2015).

[27] R. Behrisch et al., J. Nucl. Mater. 313-316 (2003) 388-392.

[28] N. den Harder et al., Nucl. Fusion 56026014 (2016).

[29] S. Lindig et al., Phys. Scr. T145 014039 (2011).

[30] Y. Ueda et al., Fus. Sci. Technol. 52513 (2007).

[31] M.J. Baldwin et al., Nucl. Fusion 48035001 (2008).

[32] M. Tokitani et al., Nucl. Fusion 51102001 (2011).

[33] J. Coenen et al., Nucl. Fusion 51083008 (2011).

[34] G. G. van Eden et al., Nucl. Fusion 54123010 (2014).

[35] C. Shuang et al., J. Nucl. Mater. 486 (2017) 267.

[36] J. Roth et al., J. Nucl. Mater. 390-391 (2009) 1-9.

[37] J. Roth et al., Nucl. Fusion 44 (2004) L21.

[38] R. Doerner et al., Nucl. Mater. Energy 9 (2016) 89.

[39] O. V. Ogorodnikova et al. J. Appl. Phys. 103 (2008) 034902.

[40] M. H. J. 't Hoen et al., Nucl. Fusion 54 (2014) 083014.

[41] M. H. J. 't Hoen et al., Phys. Rev. Lett. 111 (2013) 225001.

[42] N. Ohno et al., J. Nucl. Mater. 390-391 (2009) 61.

[43] K. Bystrov et al., J. Nucl. Mater. 415 S149 (2011).

[44] M. J. Baldwin et al., Nucl. Fusion 48 (2008) 035001.

[45] M. Tokitani et al., Nucl. Fusion 51 (2011) 102001.

[46] M. Bonitz et al., Rep. Prog. Phys. 73 (2010) 066501.

[47] V. Barabash et al., J. Nucl. Mater. 417 (2003) 42.

[48] V. Barabash et al., J. Nucl. Mater. 383-387 (2000) 138.

[49] G. A. Cottrell, Fus. Eng. Des. 66-68 (2003) 253.

[50] M. Fujisuka et al., J. Nucl. Mater. 283-287 (2000) 1148.

[51] T. Tanno et al., J. Nucl. Mater. 386-388 (2009) 218.

[52] B. Tyburska et al., J. Nucl. Mater. 395 (2009) 150.

[53] W. R. Wampler and R. Doerner, Nucl. Fusion 49 (2009) 115023. 
[54] G. M. Wright et al., Nucl. Fusion 50 (2010) 075006.

[55] M. H. J. 't Hoen et al., Nucl. Fusion 52 (2012) 023008.

[56] M. Shimada et al., J. Nucl. Mater. 415 (2011) S667.

[57] B.I. Khripunov et al., J. Nucl. Mater. 390-391 (2009) 921.

[58] V. Kh. Alimov et al., J. Nucl. Mater. 370-373 (2012) 420.

[59] R. J. Colchin et al., J. Nucl. Mater. 76-77 (1978) 405.

[60] A. J. Wooton et al., J. Nucl. Mater. 111-112 (1982) 479.

[61] P. K. Mioduzewski et al., Nucl. Fusion 27 (1987) 195.

[62] V. Philipps, Fus. Sci. Technol. 47 (2004) 119.

[63] J. Winter, Plasma Phys. Control. Fusion 38 (1996) 1503.

[64] S. Brezinsek et al., Nucl. Fusion 53 (2013) 083023.

[65] B. Lipschultz et al., Phys. Rev. Lett. 81 (1998) 1007.

[66] B. Lipschultz et al., Phys. Plasmas 6 (1999) 1907.

[67] K. Heinola et al., Phys. Scr. T167 (2016) 014075.

[68] B. Lipschultz et al., Nucl. Fusion 49 (2009) 045009.

[69] M. Mayer et al., Phys. Scr. T128 (2007) 106.

[70] K. Krieger et al., J. Nucl. Mater. 266-269 (1999) 207.

[71] Y. Hirooka et al., J. Vac. Sci. Technol. A8 (3), May/Jun (1990) 1790-1797.

[72] P.C. Stangeby and A.W. Leonard, Nucl. Fusion 51 (2011) 063001.

[73] J. N. Brooks, Phys. Fluids B 21858 (1990).

[74] N. Ohno et al., J. Nucl. Mater. 390-391 (2009) 61-64.

[75] K. Ohya, J. Nucl. Mater. 415 (2011) S10.

[76] J. Rapp et al., Fus. Eng. Des. 85 (2010) 1455-1459.

[77] D. G. Whyte et al., Fus. Eng. Des. doi:10.1016/j..fusengdes.2011.12.011 (2012).

[78] P. C. Stangeby et al., The Plasma Boundary of Magnetic Fusion Devices Taylor and Francis Group New York (2000).

[79] J. C. Glowienka, J. Vac. Sci. Technol. 18 (1981) 1088.

[80] J. Rapp et al., Nucl. Fusion 57 (2017) 116001.

[81] T. M. Biewer et al., Phys. Plasmas 25 (2018) 024501

[82] C. J. Beers et al., Phys. Plasmas 25 (2018) 013526 



\title{
APPENDIX A. BIOGRAPHICAL SKETCH
}

\section{Juergen Rapp}

\author{
Senior R\&D Staff, Program Manager MPEX \\ Nuclear Science and Engineering Directorate \\ Fusion and Materials for Nuclear Systems Division \\ Oak Ridge National Laboratory \\ rappj@ornl.gov
}

Juergen Rapp is a senior R\&D staff member at Oak Ridge National Laboratory in the Fusion and Materials for Nuclear Systems Division, where he has been employed since August 2011 and leads the program for the advanced plasma generator Material Plasma Exposure eXperiment (MPEX). Within this program, Proto-MPEX is being tested to develop the technology and the science for MPEX. He received his MS and $\mathrm{PhD}$ in electrical engineering from the University of Wuppertal, Germany, in 1991 and 1995, respectively. He started his early career on the TEXTOR tokamak at the Research Center in Juelich, Germany (1995-1999). From 1999 to 2007, he worked mainly at the Joint European Torus (JET) at Culham, UK, in various capacities: as scientific coordinator of several experiments, as session leader of more than 70 experiments, as physics officer to the JET enhancement program, and as head of operations in the European Fusion Development Agreement-JET Close Support Unit. As head of the operations department, he also supervised the Fusion Technology Work Program at JET. From 2007 to 2011 he was program leader and head of the Plasma Surface Interactions (PSI) Division in the FOM Institute for Plasma Physics in Nieuwegein, the Netherlands. In this position, he oversaw construction of the Magnum-PSI facility and operation of its forerunner experiment, Pilot-PSI. In 2011, he was appointed as part-time professor at the Technical University of Eindhoven, the Netherlands. His scientific expertise includes investigations on high- $Z$ material (tungsten, molybdenum) sources and transport in the TEXTOR, the physics of density limits in TEXTOR and JET, power exhaust and divertor physics at JET, and mitigation of steady-state and transient heat loads by impurity seeding at JET and the ASDEX Upgrade. He initiated the design of the carbon Mk-IIHD divertor on JET and was involved in the design of the solid tungsten divertor in JET. Dr. Rapp has many years of leadership experience, including 5 years in senior management at world-leading fusion facilities (JET, Magnum-PSI). He is currently developing the next world-leading linear plasma device, MPEX. Dr. Rapp has served on various committees and currently serves on Fusion Energy Sciences Advisory Committee, the ITER STAC, and the Executive Committee for the IEA technology collaboration programme on the research and development on plasma-wall interaction facilities for fusion reactors. Dr. Rapp authored and coauthored more than 400 publications, including more than 150 peer-reviewed publications that have been cited more than 4,000 times. Dr. Rapp is fellow of the American Physical Society. 
